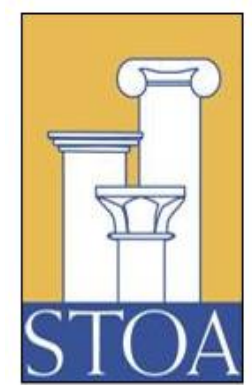

Science and Technology Options Assessment

\title{
Potential and
}

Impacts of Cloud

Computing

Services and

Social Network

Websites

Annex - Social Network Websites 



\title{
Potential and Impacts of Cloud Computing Services and Social Network Websites
}

\author{
Annex - Social Network Websites
}

IP/A/STOA/FWC/2008-096/Lot4/C1/SC8

January 2014

PE 513.546 
The STOA project 'Potential and Impacts of Cloud Computing Services and Social Network Websites' was carried out by the Fraunhofer Institute for Systems and Innovation Research (ISI), Karlsruhe (project co-ordinator); together with the Institute of Technology Assessment (ITA), Vienna; the Institute for Technology Assessment and Systems Analysis (ITAS), Karlsruhe; and the Danish Board of Technology (DBT), Copenhagen, as members of ETAG.

\section{PROJECT LEADER}

Timo Leimbach, Fraunhofer ISI

\section{AUTHORS}

Stefan Strauß (ITA)

Michael Nentwich (ITA)

\section{RESPONSIBLE ADMINISTRATOR}

Peter Ide-Kostic

Science and Technology Options Assessment (STOA)

Directorate for Impact Assessment and European Added Value

Directorate-General for Parliamentary Research Services

European Parliament, Rue Wiertz 60 - RMD 00J016, B-1047 Brussels

E-mail: peter.ide-kostic@ep.europa.eu

\section{LINGUISTIC VERSION}

Original: EN

\section{ABOUT THE PUBLISHER}

To contact STOA or to subscribe to its newsletter please write to: STOA@ep.europa.eu

This document is available on the Internet at: http://www.ep.europa.eu/stoa/

\section{DISCLAIMER}

The opinions expressed in this document are the sole responsibility of the authors and do not necessarily represent the official position of the European Parliament.

Reproduction and translation for non-commercial purposes are authorised, provided the source is acknowledged and the publisher is given prior notice and sent a copy.

Manuscript completed in January 2014.

Brussels, (C) European Union, 2014.

PE 513.546

CAT QA-01-14-012-EN-C

DOI $10.2861 / 48878$

ISBN 978-92-823-5272-4 


\section{CONTENTS}

EXECUTIVE SUMMARY 1

1. INTRODUCTION

2. OVERVIEW AND STATE-OF-THE-ART 6

2.1 The evolution of social media and the dawn of SNS 6

2.2 Major characteristics and types of SNS $\quad 8$

2.3 Different user groups and their motivations 12

3. STRUCTURE AND FUNCTIONALITY 14

3.1 Six degrees of separation and the strength of weak ties 15

3.2 Social relations and the social graph 16

3.3 Embedded services and the role of social plugins 18

4. SOCIETAL IMPACTS 20

4.1 Considerations on the public and private spheres 21

4.2 SNS and political participation $\quad 22$

4.3 SNS and knowledge production 23

5. PRIVACY IMPLICATIONS AND CHALLENGES AHEAD 27

5.1 Information disclosure and informational self-determination 27

5.2 Personal vs. non-personal data and identifiable information 32

5.3 Seven types of privacy 33

5.4 Privacy-by-design vs. disclosure-by-default 35

6. CONCLUDING REMARKS 38

REFERENCES $\quad 40$ 


\section{EXECUTIVE SUMMARY}

Cloud computing and social network websites (SNS) are part of the same societal transformation prominently exemplifying a paradigm shift stating that "the network is the computer" 1 . While cloud computing includes a variety of technical concepts, SNS represent a broad scope of services and applications addressing mostly end-users. Interrelations are particularly given as regards privacy and security challenges. This is also a core part of this report as privacy is among the heavily debated concepts of our contemporary societies - highlighted in particular by SNS.

The report is structured in four main parts: The first part (Sections 1-3) gives a broad overview on the evolution of SNS describing the main stages in the development process, the major factors determining the current state-of-the-art including insights into user motivations. Section 3 presents the main driving factors determining the current SNS, their main characteristics as well as core functionality of SNS. Based on these elaborations the second part (Section 4) gives an overview on the spectrum of identified societal impacts, discusses the role of SNS as a form of a (digital) semi-public space, as well as their potential for political participation and knowledge production. Section 5 analyses in more depth the privacy implications of SNS including some technical aspects and privacy-by-design concepts. The final Section 6 summarizes the key findings and draws conclusions referring to possible options to address the challenges identified.

\section{Major issues in a nutshell}

Contemporary SNS with their enormously high user rates worldwide and the manifold different types of applications available have a relatively short but turbulent history. The very beginnings can be traced back to the late 1980s and early 1990s with a first impetus from early web communities and interest groups. In the 1990s, the first messaging services appeared that improved options to connect with other Web users and create contact lists. During the late 1990s, with sixdegrees.com, the first profile-based SNS occurred that combined different features for self-presentation, managing contacts, and messaging. The user profile today is standard in contemporary SNS and a main part of their core architecture as profiles are the main entry points to access the SNS and its functionality.

The establishment of profile-based SNS accelerated the further development. In a relatively short period of time, a variety of different community-focussed SNS occurred. With increasing user rates, businessrelated SNS and SNS devoted to particular interest groups appeared (e.g. the music-focussed MySpace was the most popular site during the early 2000s). After Facebook entered the global stage (in about 2003), a broad spectrum of social media services (such as YouTube, Twitter, etc.) became available and SNS became part of mainstream. From this time on, we observe a trend towards integration of services and applications, transforming SNS into platforms for a broad spectrum of different features that also expand to the outside Web. Social plugins and social graphs are core developments in this regard that link SNS and other web environments; thus they are capable of affecting the shape of the World Wide Web in general.

Accordingly, the societal impacts of SNS are considerable, not least reflected in the wide global diffusion and the broad spectrum of user groups and their motivations. Despite of some particular usage patterns, the main reasons for using SNS are to continuously maintain and establish relations with friends, contacts, etc. The networking structure of SNS provides a variety of new modes of interactions to support this. To some extent, classical theories in the field of network analysis are employed in SNS functionality. Milgram's (1967) "small world problem", for instance, addressing the "six degrees of separation", i.e. that every person globally can be related over six degrees to any other, and Granovetter's (1973) hypothesis of the "strength of weak ties", claiming that loose connections have a

1 This phrase was coined by John Gage, the former Chief Researcher at Sun Microsystems. 
strong impact on network expansion as they function as bridges across different network nodes. These concepts play an important role in the growth of SNS environments. In this regard, the variety of types of content available across SNS environments plays an increasing role also in relation to the main reasons for networking. Users' interactions are often related to dealing with content (e.g. consuming, sharing, creating, etc.). By enabling and stimulating one-to-many and many-to-many interactions among personal as well as non-personal entities (i.e. content) these new modalities contribute to the selfamplifying dynamic of SNS. The widespread distribution of information in to time and among large numbers of users, groups and communities locally and globally is one core aspect in this regard. This entails a broad spectrum of positive effects, such as social learning; new options for participation; strengthening community building; developing social capital; and enhancing political empowerment. A democratic potential of SNS has been highlighted for instance by the Arab Spring Revolutions, although in an ambivalent manner. While social media channels were supportive and catalysing means for activists and democratic movements to transform the governing regimes towards democratic systems, the same channels have been used by authoritarian regimes for control and repression. Hence, social media can make a democratic difference, but only if people use it in that sense. The participatory capacity of social media is fed by the many different interactive features, which also stimulate the production of new knowledge. The variety of new possibilities for information exchange, mutual learning and collaboration is particularly relevant in scientific contexts. The increasing relevance of usergenerated content also provides valuable source for various kinds of business models.

With relations, content and interactions being both explicitly and implicitly linkable to individual users, privacy is among the most controversial issues in SNS environments. While the contemporary societies in general have to encounter many privacy challenges, SNS represent a significant part of this privacy "puzzle". One crux is the lacking distinction between user information, interactions and content. The combination of these aspects enables SNS to gain deep and far-reaching insights into user behaviour and identity. Recent innovations such as the social graph (grounding on mathematical graph theory) aim at systematically map the variety of different relations and interactions and thus aggravate these problematic aspects. These developments multiply the existing barriers for users to exercise their right to informational self-determination. The limited options for individuals to protect their privacy complicate further if the SNS architectures do not include appropriate and effective protection mechanisms. This underlines the demand for privacy-by-design concepts as integral parts of SNS environments. Respective strategies need to deal with at least two core problems of contemporary privacy protection: a disclosure-by-default paradigm exemplified by SNS, i.e. the widespread availability of personal information as standard mode; and the related increase in personal identifiable information reinforced by a convergence of personal and non-personal data as one result of the multiple interactions, not least between personal and non-personal entities. Contemporary SNS affect several different types of privacy (such as communication, data and image, behaviour and action, location). Considering emerging trends related to SNS, privacy impacts might increase further with social plugins and graphs, biometrics and face recognition technologies, as well as mobile SNS usage and locationbased services as fast growing markets.

Addressing these privacy challenges demands not least a shift of the prevailing disclosure-by-default paradigm towards a setting where privacy-by-design and privacy-by-default are the leading principles. Measures to stimulate this shift might be:

- Enforce content encryption as standard

- Foster anonymity and pseudonymity

- Strengthen freedom of information and transparency

- Raise awareness for privacy and transparency

- Stimulate innovation for privacy by design

- Strengthen the role of Data Protection Authorities to improve checks and balances 
These measures are particularly salient in the face of the recent scandals revealing large-scale surveillance of individuals on a global level. While the collateral damage caused by these scandals is yet unpredictable, they highlight urgency for a revitalization of privacy - a concept that is strongly connected to the need to recover the individuals' trust in the system. 


\section{INTRODUCTION}

\section{A global phenomenon}

Despite of their relative novelty, in no time social network sites (SNS) became a global phenomenon of contemporary societies. Starting in the late 1990s as niche applications in the World Wide Web after a first boost in 2003 and the occurrence of Facebook in 2004, SNS increasingly gained higher profile.

SNS offer novel communicative possibilities; above all they link-up its members and map their offline networks (e.g. Boyd/Ellison 2007). They are among the most rapidly spreading services in the World Wide Web; the increasing diffusion of SNS and related services on a global scale is inter alia visible in diverse website rankings (such as from the leading web metrics provider Alexa.com), where several SNS are present in top ranks, e.g. Facebook as second most popular website worldwide (right after Google), Youtube $\left(3^{\text {rd }}\right)$, Twitter $\left(8^{\text {th }}\right)$, and LinkedIn $\left(12^{\text {th }}\right)^{2}$. Though such rankings are soft indicators they refer to the growing importance and societal impact of SNS for different forms of online activities.

SNS provide a variety of low-threshold ways to establish, modulate and extend different network-based relations. Usage contexts of SNS range from private (e.g. dating, seeking friends, organising groups) to professional purposes (e.g. job seeking, education, business contacts, science and research, marketing). SNS are the most prominent example for new modes of interaction in digital environments and demonstrate the effects of many-to-many relations: SNS are not only means for single users to interact with others based on common interests, but also provide various options for user groups, organizations or institutions to present themselves to a wider public and extent their contacts (e.g. communities, grassroots, public institutions). These new modes of interaction entail a variety of new possibilities to share and create content.

The broad scope of different usage contexts essentially grounds on the sharing of personal data and information to some extent, as every form of social interaction needs a certain amount of such information. While on the one hand sharing and creating content may support community building an participation, on the other, the vast amounts of personal information being processed complicate privacy protection and user control. In this respect, SNS bear potential and real conflicts between user's intentions to socialize and disclose information and how this information is processed within the SNS environment. Hence, the interplay between SNS functionality, different usage patterns and privacy settings is a major aspect to consider in the impact assessment of SNS.

\section{Scope of this report}

As the technological basis of SNS is in many cases cloud computing, the present special report focusses on the phenomenon of SNS within the framework of this wider subject. In the beginning, the report gives an overview of the state-of-the-art, the evolution, major characteristics, different user groups, and their motivations. Chapter 3 outlines the structure and functionality of SNS, the modes of interaction, the social relations and the so-called social plug-ins. Chapters 4 and 5 focus on an assessment of the major impact dimensions: on knowledge production, on political participation, and on privacy aspects. The report closes with an outlook and concluding remarks.

The present report is no encompassing study of all possible aspects of SNS, but rather focuses on the most salient and politically most relevant issues, above all the privacy aspects. ${ }^{3}$

\footnotetext{
2 See http://www.alexa.com/topsites, May 212012.

3 With regard to the main tasks as set out in the current project plan (Technical Specifications of Phase 5, version 4 June 2013, p. 12), the reader will find the overview on the current state-of-the art and market situation of SNS mainly in Sections 2.1 and 4.3; the identification of the major factors shaping the current evolution of SNS in Section
} 


\section{OVERVIEW AND STATE-OF-THE-ART}

Social Network Sites (SNS) have their beginnings already in the late 1990s starting as niche applications. In 2003, SNS became more widespread and with the occurrence of Facebook in 2004, SNS quickly turned into a global phenomenon. SNS usage is among the most popular Internet activity with Facebook as the leading network worldwide. With 229 million active users merely in European countries, Europe is Facebook's biggest market (EC 2012a). As outlined in this section, a variety of different SNS alike services and applications occurring during the last 15-20 years contributed to the shape and diffusion of contemporary SNS.

\subsection{The evolution of social media and the dawn of SNS}

The development of SNS from a niche application towards a mainstream phenomenon happened in a relatively short period of time. Figure 1 provides some insight into the history of SNS and main stages in this development.

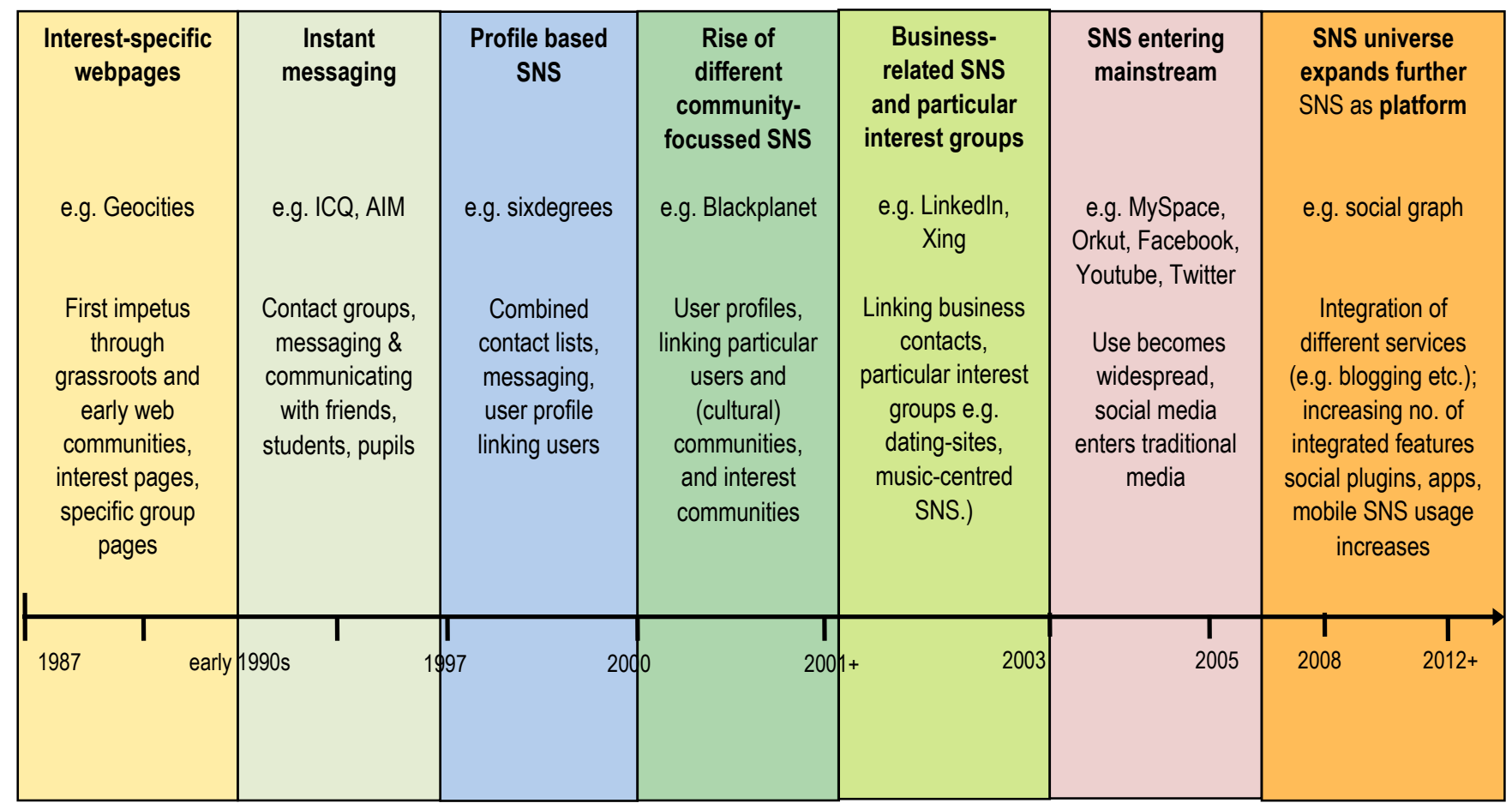

Figure 1: SNS evolution from niche to social mainstream

2.2, an overview on economic factors in 4.3, social/cultural factors in Chapter 4, with a special focus on privacy issues in Section 4.1 and Chapter 5; regulatory factors are addressed in Section 5.4; the analysis and assessment of the all factors is presented in Chapters 4 (Societal Impacts) and 5 (Privacy Implications and Challenges); and finally, the discussion of technical options and issues, such as privacy-by-design and governance challenges related to SNS in Section 5.4 as well as in the concluding Chapter 6. 
The development towards contemporary SNS received its first stimulus already during late 1980s/early 1990s. The occurrence of early web community pages and interest specific sites slightly changed the web landscape. Community pages such as Geocities, as the most prominent during that time, provided novel forms of communication. Grassroots organisations and idealistic communities such as environmental activists (e.g. Friends of the Earth) were among the early adopters making use of online community pages to exchange their visions and ideas. These sites occupied small niches in the World Wide Web where people started to exchange thoughts and ideas based on common interests. These online services represent early examples of SNS.

A next important development, triggered by the increasing employment of communication tools such as chat rooms and instant messaging (IM), fostered synchronous and livelier communication (e.g. ICQ, AIM). To some extent, these messaging services vitalized the widespread, but loosely bound online communities and provided new options to establish connections between community pages. IM services such as ICQ allowed users to create contact lists and group them e.g. in circles of friends or similar. These possibilities played a crucial role in the further development. With the increasing role of user profiles to describe the characteristics of a particular user SNS began to take more concrete shape.

In the late 1990s, the first proper SNS appeared: Sixdegrees.com was the first service that combined different features such as contact lists, instant messaging and user profiles. Since then, this combination with a user profile as the main entry point is today state-of-the-art in most SNS. This also enabled to bundle and integrate previously separated services such as chatting, instant messaging and networking in a single SNS environment. However, while sixdegrees had several million users, it was somehow not able to establish a sustainable business. Hence, despite of its leading role in the development of SNS, it had to shut down in 2000 (Boyd/Ellison 2007).

Nevertheless, the concept remained and evolved further: From the year 2000, an increasing number of different community-centered SNS started, which supported several combinations of profiles and contact lists aiming at connecting users, for instance based on their cultural backgrounds (e.g. AsianAvenue, Blackplanet) or on particular interests (e.g. dating sites such as match.com). In the next wave, SNS became increasingly attractive for commercial actors and networks focusing on businessrelated networks (e.g. LinkedIn, Xing) became more relevant and widespread. At the same time, there was a significant increase in SNS focussing on particular interests (e.g. hobbies, sports, travelling, etc.). Most prominent at that time was MySpace - the formerly most popular SNS worldwide that initially served as network for musicians and their fans.

Around the year 2003, SNS began to enter the mainstream and a variety of new SNS have been founded. In South American countries (especially in Brazil) Orkut became a very popular network and MySpace had its highest usage rates during this time. Also during that period today's global player Facebook occurred and quickly expanded around the globe. In parallel to this widespread SNS diffusion and usage on a global scale, also the role of user-generated content and social media in general boosted. As a consequence, services such as blogging, content-specific platforms (e.g. photo/video-sharing, Flickr, YouTube, etc.) have been integrated more deeply into SNS environments and are nowadays integral parts of several SNS.

Nowadays SNS can be seen as part of social mainstream shaping the Internet experience of many users worldwide; at present, major players like the ubiquitous Facebook or Google+ count several hundred million users 4 . In addition to the major operators a variety of specialized network sites exist with different usage contexts ranging from dating or friend seeking to professional use such as job seeking, education, business contacts as well as in science and research (e.g. LinkedIn, Xing, Yammer,

\footnotetext{
4 Facebook seems to have reached a billion users http://money.cnn.com/2012/10/04/technology/facebook-billionusers/index.html, and Google+ about 500 million user http://techcrunch.com/2012/12/06/google-sharesnumbers-more-than-500m-upgraded-235m-active-across-google-135m-in-the-stream/.
} 
Academia.edu, ResearchGate). As SNS evolve fast as regards usage and scope of applications integrated, also services such as micro-blogging (e.g. Twitter), video platforms (e.g. YouTube), social bookmarking services (e.g. Delicious) or news aggregation tools (e.g. Reddit) can be considered as SNS.

The phase of integration is still on-going and SNS seem to increasingly serve as platforms for many services and applications that become more and more integrated into SNS environments. The rise of socalled social plugins play a particular role in this transformation of SNS towards a platform that trigger further expansion of the SNS universe across the (outside) web (see section 3.3).

\subsection{Major characteristics and types of SNS}

One major peculiarity of social network sites lies with its general capability to enable individuals in articulating and showing their social networks in a novel form of digital environment.

There are various attempts in the literature to define social network sites (or similar notions, often used synonymously, like social networks, social network[ing] sites or services or platforms, see Mack et al. 2007; Richter/Koch 2007; Schmidt 2009), some are more encompassing, some less. One of the most prominent definition of SNS is the one by Boyd and Ellison (2007) who define SNS as

"[...] web-based services that allow individuals to (1) construct a public or semi-public profile within a bounded system, (2) articulate a list of other users with whom they share a connection, and (3) view and traverse their list of connections and those made by others within the system."

This definition offers a broad view on SNS that already embraces a wider set of services and applications (such as photo or video-sharing, blogging or news aggregation tools etc.), albeit in an implicit manner. Such a broad view makes much sense as the functionality of SNS has evolved and expanded further. To underline the role of sharing and creating content, Ellison and Boyd (2013) updated this definition:

"A social network site is a networked communication platform in which participants 1) have uniquely identifiable profiles that consist of user-supplied content, content provided by other users, and/or system-provided data; 2) can publicly articulate connections that can be viewed and traversed by others; and 3) can consume, produce, and/or interact with streams of usergenerated content provided by their connections on the site." (p. 158)

This updated definition also highlights the platform character of contemporary SNS that bundle a variety of additional features for handling contacts and content.

In line with this view, the following major characteristics of SNS can be identified (Boyd/Ellison 2007; Ellison/Boyd 2013; Nentwich/König 2012):

- A user profile, i.e. a unique web page providing details of a user, serving as the main (bidirectional) access point to the SNS environment. Profiles are central network nodes, which can be addressed through various channels.

- A public (or semi-public) display of connections; i.e. a list of contacts (e.g. friends, colleagues, etc.) that also shows the connections between the user and his/her contacts.

- The option for users to navigate across those connections (e.g. viewing profiles that are associated with the list of contacts).

- Communication and interaction features such as instant messaging, chats, internal e-mail, bulletin boards, etc. to interact with other users and/or user-generated content.

These main characteristics are interrelated and build the baseline for the functionality of most SNS. Although many additional features exist, they mainly ground on these core components. The following sub-section describes these characteristics and related features more in-depth. 


\section{SNS in details}

The user profile plays a particular role as it is a digital representation of the user and as such provides the central node and single entry point, sort of single-sign-on, that enables access to all the SNS functionality. In some SNS it is also possible to have specific profiles for organizations. Thus profiles are like enhanced calling cards of individuals, organizations and groups. Two core functions of the profile are always present: identity management and contact management (cf. Richter/Koch 2007). The profiles map - more or less in the public domain - the contacts of a person and enable access to further members on various paths, i.e. networking. Via their profile, users are linkable to others and visible inside (and outside) the network environment. A user profile usually contains the following (pre-structured) information:

- Contact information (e.g. address, e-mail, phone, website)

- Personal information (e.g. date of birth, interests)

- Pictures of users and other photos

- Status messages (micro-blogging on current events etc., indications regarding one's professional and personal relationship status etc.)

- Tracking of user activities (e.g. messages regarding changes of the profile, the joining of groups etc.)

- Record of contacts, affiliation to groups, etc.

This information is usually visible to other members of the SNS. The degree of visibility depends on the particular settings of the SNS environment. To some extent, users can define in their SNS accounts which data should be visible to others (e.g. all members of the SNS or only certain contacts/friends).

The list of contacts is a core component for the networking functionality representing a user's connection to others. Around this basic function there are various tools embedded to stimulate networking, such as:

- Contacts/friends: Network members can add other members, represented by their profiles, as "contacts" ("friends" in Facebook) and can administer them in lists and groupings. As a rule, the other member has to confirm the contact request; in some SNS it is possible to unilaterally "follow" another member (e.g. ResearchGate).

- Automated propositions: On the basis of semantic analysis of the information given in profiles and the activities of the members, the SNS produces proposals for new contacts, related groups, interesting publications or events, etc.

- "Manual" propositions: Other members can trigger requests and recommendations by themselves.

- Search function: Users may find members, groups etc. by search terms.

- Automated search of potential contacts is supported via the contact lists of one's own e-mail, microblogging or other $\mathrm{SNS}^{\prime}$ account.

- Invitation: Users can invite potential new members via external e-mail (possible with most SNS), also with tracking of invitations (e.g. ResearchGate).

- Bookmarking of profiles, in order to keep persons in mind who are no contacts or whom one does not follow.

- Automatically generated requests to welcome new members or propose something or someone to them (e.g. Ning, Facebook).

In line with the ability to navigate a user's network, these tools support network presentation in various forms: as a list of all contacts or all members like a directory; visualization and analysis of one's own network in form of an interactive picture or social graph (see section 3.2).

Communication and interaction within the network is at the very core of the SNS and provided by many different features such as:

- Start/news page: The personal start pages present in structured manner information about the current events within the SNS. They show status messages and further activities of one's contacts as well as news, dates, contact requests, propositions, etc. 
- Web-based messaging: Bilateral sending and receiving of simple text messages between individual members or groups. Some platforms (e.g. Facebook) also offer e-mail addresses, hence allowing even non-members to contact their users.

- Chatting: Synchronous instant messaging among individual members.

- Discussion forums/groups: Thematic groups offer a forum-like space for discussion and exchange.

- File upload: Users may upload documents, photos and other files in order to make them accessible to others.

- Micro-blogging (e.g. Twitter): By writing textual status messages one can notify contacts/friends according to the one-to-many principle. Sometimes one can include pictures, videos and external links directly in the message.

Nudging functions: Via "poking" (Facebook) one can make other members aware of oneself, without necessarily having any follow-up communication.

- External notifications: Without being logged into the SNS, users are kept informed via e-mail of all kind of news (contact requests, group information and invitations, uploads, status messages, new events, etc.).

- Content-centred functions: By one-click sharing content with others (sharing-function) or revealing their opinions (like/dislike button) on particular content (e.g. photo- or video-sharing), contributions of other users may get additional attention. This may concern individual comments or status messages, but also certain profiles, links to external offers, etc.

The listing above is only an excerpt of common features; some SNS have additional features ranging from video-conferencing tools, calendars, blogging platforms, wikis for collaborative document management to project management tools or even digital archives (e.g. in science-focussed SNS, see Nentwich/König 2012, pp. 19ff.).

In addition to the internal features, there are also many features from external third party providers embedded in the SNS environment that can be accessed by users, so-called "apps". Besides the integration of prominent services such as Skype or YouTube, examples are many different kinds of services for entertainment (e.g. TV series, movies, music), traveling, sports, etc. Prominent are different kinds of social games (e.g. Farmville). Apps are often related to the integration of advertisement which is a further relevant issue in this regard. A particular case of embedded services are so-called "social plugins" that aim at fostering interactivity between users and their content. Most prominent examples are Facebook's "like"-Button and the "Share-this" function. Via these features, users can share content with others and reveal their opinions on particular content (social plugins are discussed further in section 3.3).

The increasing number of apps and integrated external features indicates that SNS are more and more transforming into platforms for a wider array of services reaching also outside the original network.

The features, functionalities and modalities in SNS are often quickly evolving and changing. In this regard, SNS can also be understood as a hatchery for testing new applications and technologies (e.g. Facebook's obligatory introduction of the "timeline" feature or the myriads of changes in its interface). From the user's point of view this often entails significant changes in user requirements and challenges the effectiveness of privacy settings (see section 5.1).

\section{Types of SNS}

The number of globally available SNS is high and covers a broad spectrum of different usage purpose along the line from general to more specific interest-focussed contexts. Table 1 below gives some examples of contemporary SNS, distinguishing between general and interest-specific SNS. The former are characterized by their rather broad and unspecified purpose of usage, and the latter more focussed aiming at serving particular interest groups. The table only provides a brief overview on SNS and does 
not give a comprehensive image of the wide range of existing social network sites but gives an impression of the heterogeneity and quantity of contemporary SNS; ranging from sites with less than hundred members to those serving millions.

Table 1: Examples of contemporary SNS

\begin{tabular}{|c|c|c|c|}
\hline Name & Members & Access & Focus/Description \\
\hline \multicolumn{4}{|l|}{ General SNS } \\
\hline Facebook.com & 1.000.000.000 & Free & Global \\
\hline $\begin{array}{l}\text { Google+ } \\
\text { (plus.google.com) }\end{array}$ & 500.000 .000 & Free & Global \\
\hline Bebo.com & 117.000 .000 & Free & Global \\
\hline Orkut.com & 100.000 .000 & Free & Popular in India and Brazil \\
\hline MySpace.com & 30.000 .000 & Free & US and global \\
\hline Cyworld.com & 24.000 .000 & Free & Popular in South Korea \\
\hline $\begin{array}{l}\text { VZ group } \\
\text { (www.studivz.net) }\end{array}$ & 17.000 .000 & Free & $\begin{array}{l}\text { Popular in German- } \\
\text { speaking countries }\end{array}$ \\
\hline Diaspora.com & 370.000 & Free & $\begin{array}{l}\text { Decentralized, privacy- } \\
\text { friendly }\end{array}$ \\
\hline \multicolumn{4}{|c|}{ Interest-specific SNS } \\
\hline LinkedIn.com & 200.000 .000 & Premium & Business \\
\hline Badoo.com & 114.000 .000 & Free & Dating \\
\hline Flixster.com & 63.000 .000 & Free & Movies \\
\hline Flickr.com & 32.000 .000 & Free & Photos \\
\hline Last.fm & 30.000 .000 & Free & Music \\
\hline Foursquare.com & 20.000 .000 & Free & Location-based mobile SNS \\
\hline Meetup.com & 15.000 .000 & Free & Local events \\
\hline Xing.com & 11.400 .000 & Premium & Business \\
\hline Couchsurfing.com & 3.000 .000 & Free & Travelling \\
\hline Netmums.com & 1.500 .000 & Free & Parental advice \\
\hline ResearchGate.net & 3.000 .000 & Free & Science \\
\hline Academia.edu & 4.700 .000 & Free & Science \\
\hline Athlinks.com & 140.000 & Free & Sports \\
\hline
\end{tabular}

Source: Adapted from Nentwich/König (2012); data mostly as of mid-2013

Table 1 is only an excerpt of the wide range of SNS as the amount of services offered still increases in particular as regards special interests. ${ }^{5}$

5 Besides specific interests for persons there are even SNS available with profiles for pets (e.g. mysocialpetwork.com). 


\subsection{Different user groups and their motivations}

While the characteristics described above are similar in different sorts of SNS, they differ according to the particular SNS type and related user groups. The usage purposes might vary and depend on the focus of a particular social network. An interest-specific SNS pre-defines (at least to some extent) the usage context. For instance, an SNS about movies is likely to have no or minor communities related to business or research as compared to those addressing these purposes. SNS that aim at special user groups with a sort of pre-defined professional scope (e.g. ResearchGate aiming at researchers, LinkedIn or Xing for business contacts, etc.) provide a more explicit option for personal reputation management and networking in a professional sense. Opposed to those, general SNS like Facebook or Google+ seem to have practically no focus on any specific target groups, but rather aim at maximizing the amount of users. These different foci can be expected to have certain impacts on the ways users interact with the SNS and their perceptions and expectations of usage.

Social network sites are particularly known as phenomenon predominantly used by younger people. In recent Eurostat surveys from 2012 this is confirmed as $86 \%$ of the SNS users aged 14 to 25 and $69 \%$ in the group of 25 to 34 year-olds. However, SNS seem to become more popular also among elder generations: Almost $50 \%$ of the $35-44$ year-olds and 35\% of $45-54$ year-olds stated to have participated in SNS during the last three months (EC 2012a).

The activities conducted in SNS are manifold, ranging from posting pictures and videos, whether found somewhere else in the Internet or self-produced, sharing links to websites deemed interesting for others, to bi- or multilateral chatting (synchronous) or mailing (asynchronous), group discussions, asking for help or advice, advertising events, expressing opinions about practically everything, be it in short written comments or just by clicking a "Like" button or similar, sharing files, etc. Apart from the wealth of instantaneous communication among friends and near-strangers, the role of user-generated content is increasing enormously, as compared to the previous Web 1.0, in which professional or institutional content providers dominated.

Several studies exploring the motivations of SNS users show that connecting continuously to others and maintaining contact and relations with friends, relatives and acquaintances is the main function for most SNS users (cf. Smith 2011; Singh et al. 2012; Schaefer 2008; Brandtdaeg/Heim 2009). As outlined in section 2, online communities had some impact on the evolution of contemporary SNS. Hence, on a general level, the motivational factors for participating in such communities are likely to be relevant also in SNS usage. Previous studies in this regard identified several motivational factors such as finding people with shared interests, sharing experiences and needs, establishing supportive and sociable relationships, belonging to a social community and a sense of shared identity (cf. Brandtdaeg/Heim 2009; Rheingold 1993; Preece 2000; Waterson 2006). In mass communication theory, four major motivational needs are important: 1) information,2) entertainment, 3) social interaction, and 4) personal identity (McQuail 1994). In their analysis, Brandtdaeg and Heim (2009) tied in with these general factors and explored the most important reasons for using social media of 1200 users. According to their results, the five top ranking reasons are establishing new relations $(31 \%)$, connecting with friends and acquaintances $(21 \%)$, socializing (14\%), information gathering (10\%) and discussing/debating different issues $(6.5 \%)$. The authors highlight that these factors have to be seen as interrelated, not separated from each other. Schaefer (2008) explored the motivations and usage patterns among members of a business SNS. According to her findings, the most important motivations are "keeping in touch" $(72.7 \%)$, "reactivating lost contacts" (66.5\%), "managing the existing network" (64\%), "having an online address book" (38.1\%), "communicating with contacts" (33.5\%) and "visibility and self-representation" (32,7\%). Less than $30 \%$ of the respondents stated "to establish new contacts" (Schaefer 2008). The results also show that it is highly unlikely among the majority to connect with others that are completely unknown to them. At the same time, meeting and communicating regularly is also very unlikely. On the contrary, persons that "have met at least once" followed by "know each other, but not personally" are highest 
ranked. At least over $50 \%$ of the users included unknown persons into their contact lists. Hence, in business-focussed SNS offline and online social networks seem to overlap to some extent; the establishment of new relations seems to depend widely on whether a new contact is perceived as relevant in the professional context.

In a large-scale survey of over 4000 social media users on a global scale, Singh, Lenert and Bostick (2012) analysed usage patterns for business and personal use in North America, Europe and Asia. They found, on the one hand, emerging similarities in both usage categories; on the other hand, they point out that there are unique local preferences in the countries in the way social media are utilized. "It is evident, that Facebook, LinkedIn, MySpace, and Twitter usage is not uniform across the world, and there are significant differences in terms of cross-regional preferences for these social media platforms" (ibid, 698). Despite of these regional differences, the regions show similar results regarding the highest ranked reasons to connect with friends and family for private use as well as building contacts for business usage. The figures below show the results in the EU:

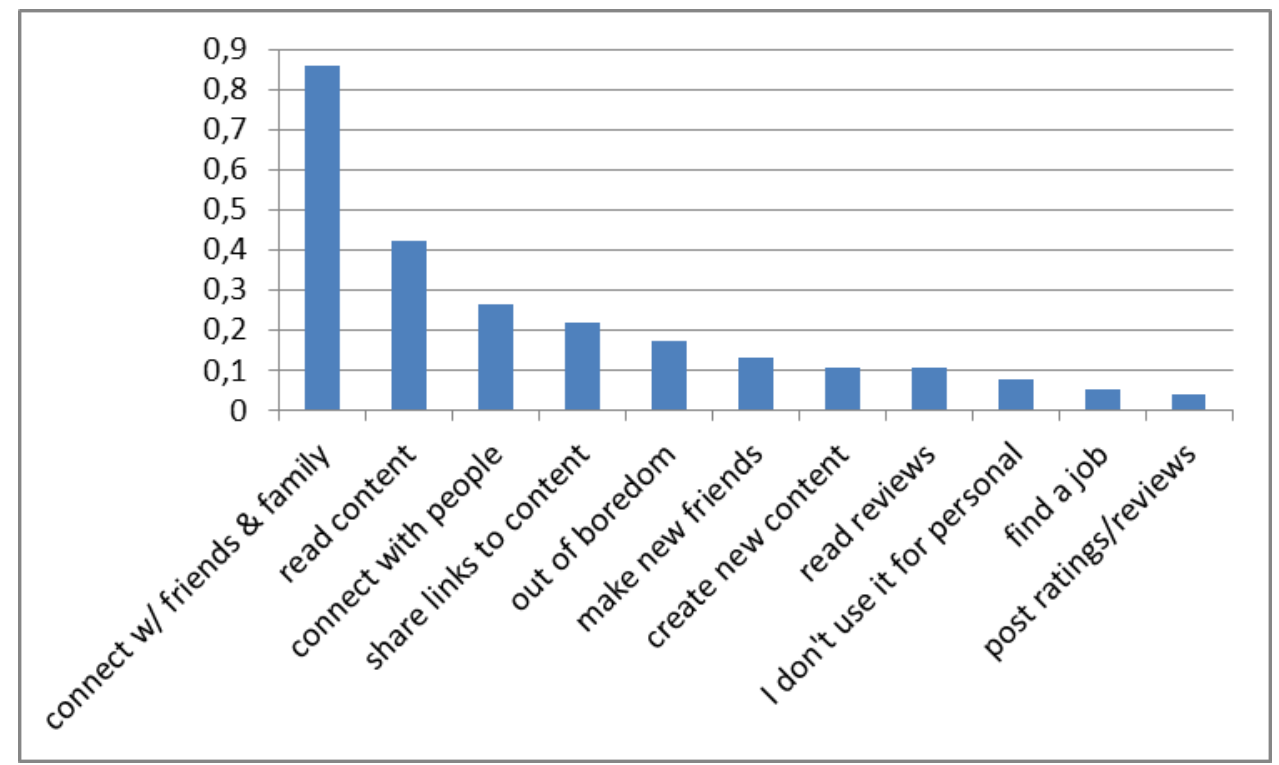

Figure 2: Personal use

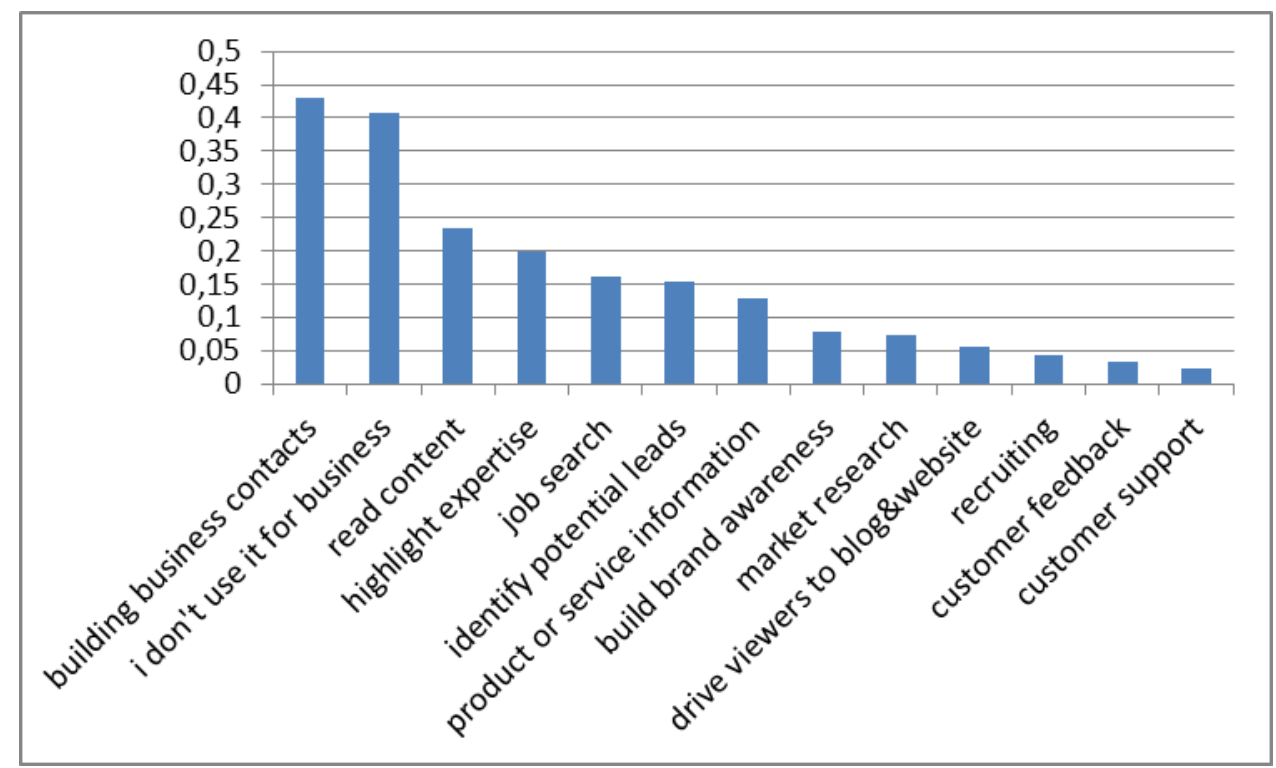

Figure 3: Business use 


\section{STRUCTURE AND FUNCTIONALITY}

The rapid expansion of SNS revitalized McLuhan's (1964) "the media is the message": merely using social media entails that information is disclosed within the network. Even if a user does not actively post information in his profile, the sheer presence of the profile is information that becomes processed in the SNS environment. With its networking character, SNS environments have a self-amplifying dynamic inherent in its design: the number of users is likely to grow if networking among them increases. "The gain in potential for a message to spread within the network (and the increase in uncertainty about how far it will in fact spread) does not grow steadily with the growth of the network - but can follow a pattern more akin to exponential growth depending on the structure of the network."

Even if a user would intend so - the very mechanisms of SNS make it relatively difficult to remain in traditional modes of interaction, i.e. one-to-one relations. The networked environments inherently enable and stimulate one-to-many relations and interactions from the individual user's point of view. This circumstance opens up a wide array of new modes of interaction. In general, the features included in SNS enable various types of interaction among users (one-to-one, one-to-many and few-to-few) and between users and software agents (searching; proposals based on semantic algorithms). In addition, the integration of external applications (such as micro-blogs) increases the density of communication among those not present in the same place.

Despite of the many different SNS, most of these systems are similar regarding their basic structure and functionality. The very idea remains the same, to enable (dynamic) relations between different entities. The implementation of this idea consists of many different components. Figure 4 shows a simplified model of some of the main building blocks of a typical SNS structure.

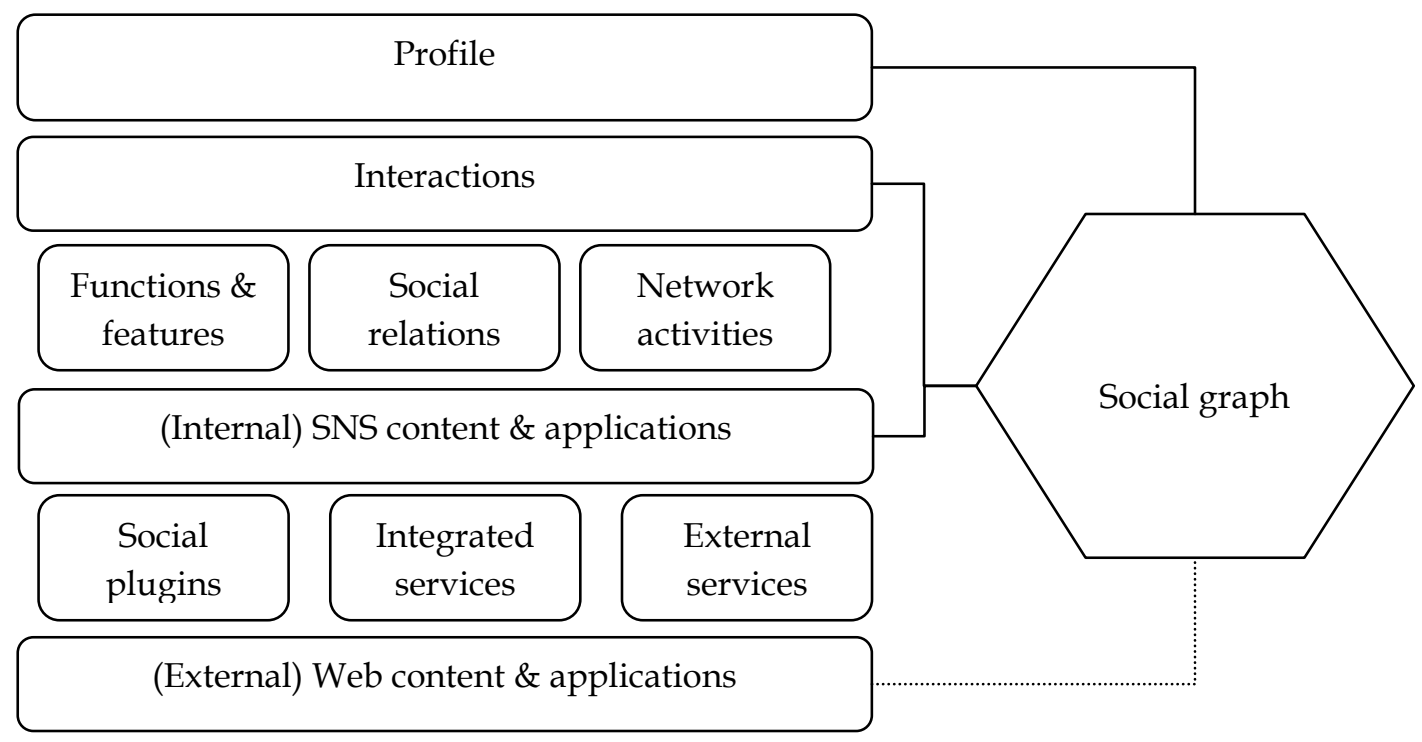

Figure 4: Main building blocks of a typical SNS structure

Source: Own representation 
From a user's point of view, his or her profile is at the core of the SNS. As already mentioned it represents the main access point to the wide array of interactions offered within the SNS environment. In the centre are the social relations, i.e. the user's circle of contacts, groups, etc.; different internal functions and features stimulate further interaction; the network itself provides tools to automatically inform about activities in the domains a user is related to. These interactions generate new content and via applications the user can also proactively include content into the network (e.g. by posting, sharing, etc.). Although strongly interrelated, there are two content and application layers that can be distinguished: the internal one within the SNS environment and the external one that crosses the border to the outside Web via external services and social plugins. Each of these building blocks generates large amounts of information that is processed further in the SNS environment and to some extent fed into the social graph (see section 3.2).

These structural aspects shape the functionality of SNS environments. Considering the major characteristics of SNS (as described in section 2.2) from a wider perspective, the SNS functionality consists of the following core features (cf. Cachia 2008, p. 3):

Table 2: Core features of SNS

\begin{tabular}{ll}
\hline Feature & Description \\
\hline Presentation of oneself & Via the profile as main entry point in most SNS and their \\
& starting pages, users can present themselves and content \\
& they want to share to other peers. \\
\hline Externalisation of data & The display of connections, i.e. the list of contacts, serves \\
& two functions as it allows users to view their networks and \\
& at the same time present to share it with others. \\
\hline New ways for community formation & $\begin{array}{l}\text { As SNS enable novel forms of interaction with a variety of } \\
\text { features, people have multiple ways to connect from } \\
\text { person to person as well as via digital objects in embedded }\end{array}$ \\
& applications, tags etc., i.e. via user-generated content. The \\
& array of connections extends also to non-personal entities. \\
\hline Bottom-up activities & $\begin{array}{l}\text { In line with the new possibilities for community building, } \\
\text { networking effects are stimulated and individuals have } \\
\text { enhanced options to share interests, ideas and collaborate. }\end{array}$ \\
\hline Ease of use & $\begin{array}{l}\text { The relative simplicity of SNS allows people with basic } \\
\text { Internet skills to create an online presence without web } \\
\text { design or programming skills and mostly without } \\
\text { additional costs. }\end{array}$ \\
\hline Reorganisation of the Web environment & $\begin{array}{l}\text { SNS created new access points to Web services that are to } \\
\text { some extent separated from the outside Web. In this regard } \\
\text { SNS foster a centralization of Web environments. }\end{array}$ \\
\hline
\end{tabular}

\subsection{Six degrees of separation and the strength of weak ties}

As the term implies, networking and interactions among users within a specific virtual environment is a core feature of SNS. Though SNS are a recent phenomenon, already classical studies about social interactions and networking such as Milgram's exploration of the "small world problem" (Milgram 1967), stating that every person knows every other person worldwide over six degrees of contacts provide valuable insights into the modes of user interactions. The "six degrees of separation" also provided the name for the first SNS sixdegrees.com (see section 2.1). In her critical analysis, Kleinfeld 
(2002) relativizes the small world theory by pointing out several biases in different studies on the small world problem, e.g. as regards the selection of samples and that the experiments conducted often failed to prove the six degrees hypothesis. "Rather than living in a 'small, small world' we may live in a world that looks a lot like a bowl of lumpy oatmeal, with many small worlds loosely connected and perhaps some small worlds not connected at all. Milgram's 'small world' theory could be viewed as the 'strong' form of the small world phenomenon, for which we have little empirical evidence. The 'lumpy oatmeal' theory, that we live in a world with many small worlds possibly, but not necessarily connected, might be viewed as the 'weak' form of the small world phenomenon, for which we do have evidence" (Kleinfeld 2002, p. 65). Despite of this critical view, there are also more recent studies than Milgram's exploration that examined the small world hypothesis in the context of Internet communication. For instance, Leskovec and Horvitz (2008) analysed 240 Mio. Instant-messenger accounts in this regard and came to similar results: every user knows every other user over approx. 6,6 knots. However, while mathematical studies exist revealing even less than six degrees, this might not correspond with societal reality: "[W]e may live in a world where everyone is connected by a short chain of acquaintances, but it is hard for most people to find these connections" (ibid, p. 66).

A further classical theory that SNS are related to is the theory of "the strength of weak ties". This theory deals with the different forms of connections in a social network. In his classical work, Granovetter (1973) identified the dimensions of time, emotional intensity, intimacy, and reciprocity as factors shaping the strength of a tie. Strong ties refer to close relations as between friends and relatives. As these connections are built on a certain amount of trust they are stabilizing factors for the consistency of a network. Weak ties are more loose connections, but they have strong influence on the growth of a social network. With their bridging function across different network domains or nodes, a network can expand. Via weak ties, content (or more general) information can be distributed more widely and traverse greater social distance than via strong ties (ibid). Hence, contacts that are loosely bound to other contacts are expected to have a wider network and thus might also benefit from extended access to information (Heidemann 2010).

The strength of weak ties is well demonstrated by the success of the micro-blogging service Twitter: the aim of this service is to provide a simple way to distribute information across the network. The more followers a twitterer has, the more likely that the information (the tweet) crosses bridges to other network nodes or communities. Opposed to that, information distributed through strong ties "is much more likely to be limited to a few cliques than that going via weak ones; bridges will not be crossed" (Granovetter 1973, p. 1366). However, if ties are too weak, this might have negative effects on the perceived reliability and trustworthiness of a contact. As a consequence, relations might become what Granovetter (p. 1361) calls "absent ties", defined as "ties without substantial significance" or even a "lack of any relationship". Hence, strong ties are essential for the stability of a network and, in their relation to weak ties, also ensure a fluid information flow.

\subsection{Social relations and the social graph}

Social network environments are emerging phenomena with high complexity that not least depends on the amount of users and entities including their relations within the network structure. Suitable tools to deal with network complexity are mathematical graphs that allow modelling the relationships between network entities. Social network analysis makes use of graph theory: a social graph is an attempt to deal with the complexity of social network environments. The general aim is to identify the number of actors and their relations among each other in the network (cf. Nextmedia CSA 2010). The relevance of an actor depends not least on the number of relations to other actors. Central actors with a high number of relations represent hubs or nodes. Figure 5 below shows an example of social graph visualization: 


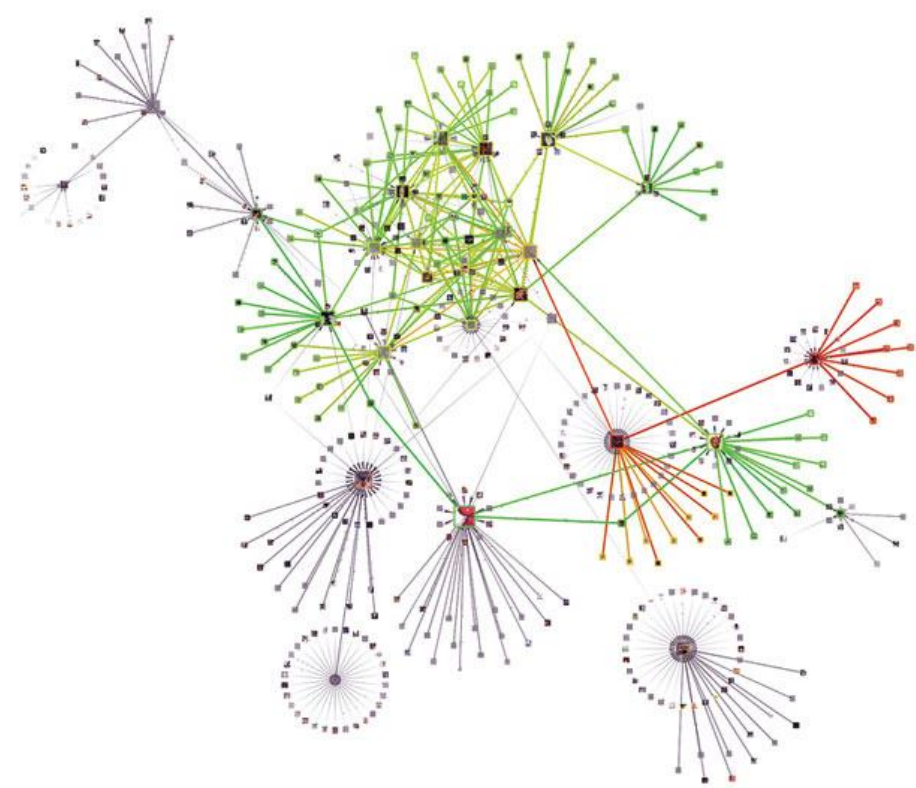

Figure 5: Social graph visualisation in ResearchGate

In general, social graphs allow to model real-world interaction and enable deeper insights into user behaviour. This does not merely incorporate relations between human entities but already addresses also digital objects, i.e. content related to a human entity. The social graph is a dynamic way of modelling relations and thus different types can be distinguished; e.g. regarding the context of the analysis. Jin et al. (2013) identify the following four different types of social graphs:

1. Friendship graph to map the relations among users

2. Interaction graph to visualize the interactions of users

3. Latent graph to show latent forms of interactions such as profile visiting

4. Following graph to reveal the distribution of followers/followees e.g. in micro-blogging.

Social graphs make use of the theoretical concepts outlined in the previous section, i.e. the six degrees of separation and the strength of weak ties. As SNS provide rich environments as regards information on social relations and interactions they are ideal sources for the application of social graphs. Hence, most SNS utilize social graphs to analyse their networks but some also introduce it as part of their functionality available for users. For instance, Facebook offers a particular search in the social graph that addresses aspects of the semantic web: it allows, for instance, to search for persons with particular interests, places they have visited, pictures a user likes, etc. ${ }^{6}$ In addition, there is also a standardized application programming interface (API) for developers available (i.e. the open graph), which enables web pages from the outside web environment to be interconnected with the social graph. The integration of social plugins into web pages is the most common practice to establish such a connection between the SNS and other Web environments (see next section).

${ }^{6} \underline{\text { https://de-de.facebook.com/about/graphsearch }}$ 


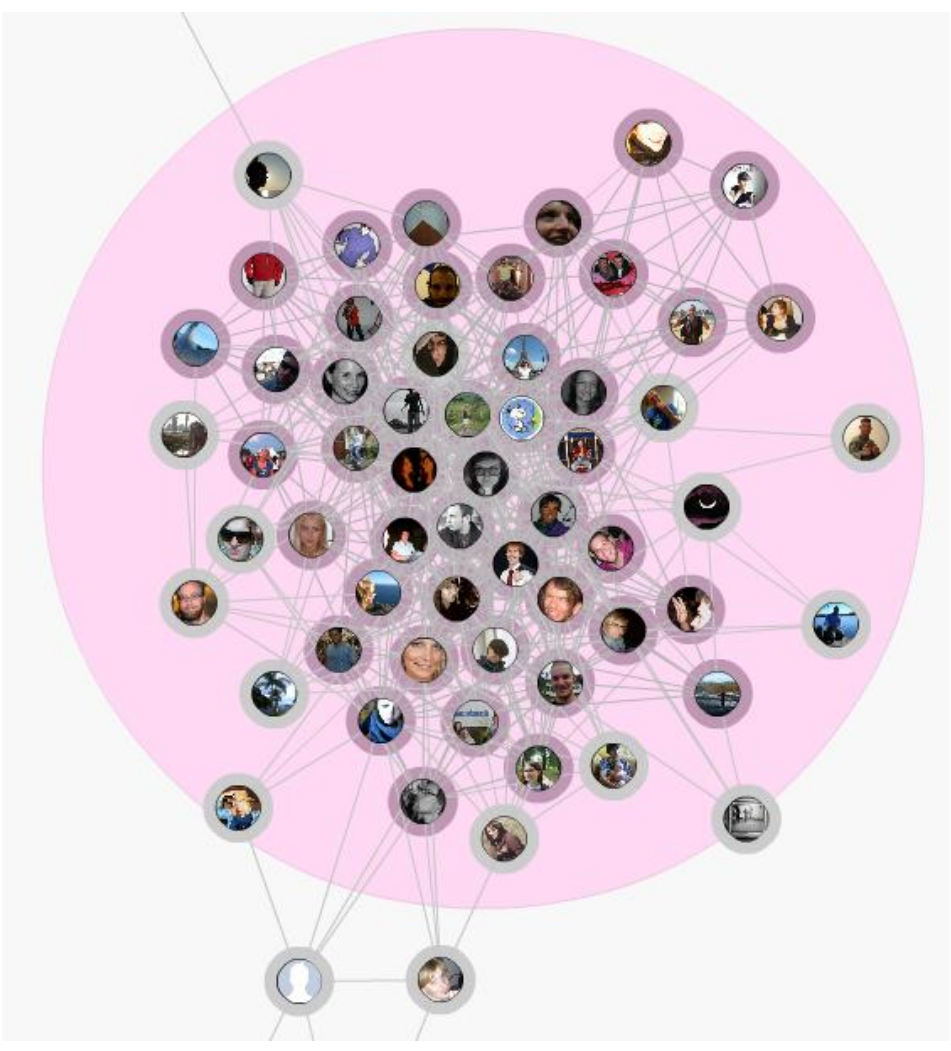

Figure 6: Example of Facebook's social graph visualization

\subsection{Embedded services and the role of social plugins}

Besides the internal SNS features, there are also many applications from external (third party) providers embedded in the SNS environment that can be accessed by users, so-called "apps". There are many different apps available (most are entertainment related such as social games like Farmville, quizzes, puzzles, applications for music, shopping, travelling, etc.). ${ }^{7}$ Several SNS also provide standardized programming interfaces for developers (API) to integrate apps. The development and integration of such applications is not least determined by commercial interests and targeted advertising.

A particular case of embedded services are so-called "social plugins" that aim at fostering interactivity between users and their content. Social plugins are standardized applications to establish a connection between an SNS and other Web environments. The most prominent social plugins are Facebook's "like", "share", "follow" and "send" buttons, which are included in many Web sites. Via these features, users can share content with others and reveal their opinions on particular content. These data is inter alia used for advertising and enables a significant extension of the SNS environment as it provides deeper insights into user behaviour referring to social search (e.g. Biermann 2010). The image below shows a screen shot of Facebook's available plugins.

\footnotetext{
${ }^{7}$ A variety of apps is available e.g. in Facebook's App Center https://www.facebook.com/appcenter.
} 


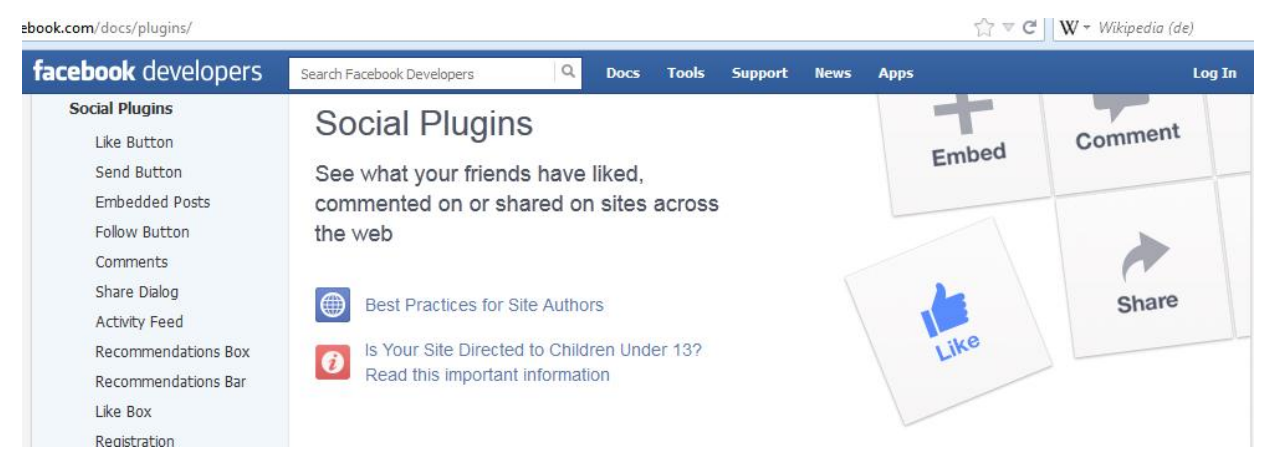

Figure 7: Social plugins available in Facebook

Source: http:// developers.facebook.com/plugins

These seemingly small applications enable the SNS to gather large amounts of information about individual user interactions in the Web outside the SNS. This includes inter alia what one likes, with which one shares what, which comments one posts on particular content, which websites and services one uses, etc. In short, they gather elements of a very detailed picture of individual usage patterns on the Internet. The functionality is relatively simple but sophisticated: a plugin establishes a direct connection with one or more servers of the original SNS environment. The SNS (e.g. Facebook) then traces every interaction with this social plugin such as clicking a like button or commenting a post, etc. If the individual interacting via a social plugin is a member of the SNS, this information feeds into his profile data. If the user is not a SNS member, the information is still collected and likely to be stored in a separate profile for non-members including identifiable data from the user's machine. 


\section{SOCIETAL IMPACTS}

The usage and impact of SNS has already been explored in various studies, covering sociological aspects (e.g. Ellison et al. 2007; Wanhoff 2011; Röll 2010; Steinfield et al. 2008), psychological issues such as Internet addiction (e.g. Valkenburg et al. 2006; Livingstone 2008) and commercial aspects, such as the business models of SNS and related companies, including data mining for marketing and other purposes (e.g. Elmer 2004; Häusler 2007; Fraser/Dutta 2008) as well as academic usage (e.g. Nentwich/König 2012). Some of the studies focus on usage and non-usage as well as usage patterns in particular (e.g. Hargittai 2007), often times with a particular focus on young users (e.g. Amanda/Mary 2007). Many studies on SNS focus on privacy and trust (e.g. Fuchs 2009; Fuchs 2010; Gross/Acquisti 2005; Biermann 2010; Ferdig et al. 2008; Lehavot 2009; Lewis et al. 2008; Barnes 2006; Cain et al. 2009; Lack et al. 2009; Dwyer et al. 2007). Further hot issues are the potential misuse of SNS (including risks for child safety, emotional abuse, online bullying etc., see e.g. Boyd 2007). Opposed to those critical aspects, there is a variety of positive effects such as stimulating social learning, enabling new modes of participation, strengthening community building, development of social capital and empowerment (e.g. Wimmer 2009; Pratchett et al. 2009)(Heidemann 2010; Hoffman 2009).

However, these potential effects are only partially showing up in the reality of common SNS usage. The visionary views on the prospects of SNS particularly as regards linking citizens and the public sector are relativizing somehow as contemporary SNS are nowadays a mainstream phenomenon. While some of the envisioned effects are observable in particular contexts, every-day-usage practices of most users seems to follow similar mechanisms than in the analogue world; i.e. the main reasons for SNS usage are to fulfil the societal need to communicate and exchange with other individuals. Studies on user behaviour and motivational aspects for SNS usage correspond to this assumption: The main reason is staying in touch, maintaining contact and relations with friends, relatives and acquaintances. Publishing and generating content such as sharing photos, music, likes etc. is an essential part of SNS usage patterns. A further aspect related to the value of content concerns the entertainment factor. The content in SNS environments (e.g. videos, photos, games etc.) often has an entertainment value for users. "Many people spend time surfing the online social networks browsing through the content in similar fashion as people watch television" (Rantamäki 2008). However, the content differs from traditional media such as radio or television as users do not merely redistribute but also create content themselves or put existing content into completely new contexts. This additional value of SNS is one aspect for its popularity.

The fact that entertainment aspects are present in SNS does not narrow the given effects of SNS but underlines that the context of usage plays a crucial role in this regard. The rather simple assumption that the more specific a usage context is given in an SNS the more likely are effects in the scope of this context. Examples in this regard are given in the scientific use of SNS. Nentwich and König (2012) provide a deeper analysis of SNS in the context of science and research.

Despite of the manifold different usage contexts, sharing personal data and information play an essential role in the very design of SNS as every form of social interaction needs a certain amount of information about the parties involved. On the one hand, the wide range of new possibilities for content-sharing and creating supports community building and collective actions; on the other, it further stresses informational privacy and the users controllability over his/her personal information in several ways (and not least due to complex modes of data processing that refer to distributed computing in the cloud). Or in other words: the distinction between personal information and user content diminishes further within social networks.

Thus, privacy, trust and proper handling of personal information are crucial aspects of SNS. In this regard there are potential conflicts between users' intentions to share personal information and the way these information is used by the SNS (e.g. behavioural targeting and processing of user data for commercial interests). These issues are not least affected by the interplay between privacy awareness, different usage patterns and features supported by the SNS. 
As seen in the case of sixdegrees, not every SNS from the early days survived in the tides of web evolution. Most prominent is the fall of Friendster, which encountered serious problems ending up in a collapse. The main reason for this collapse was a lack of functionality to handle different groups of contacts and the possibility to distinguish e.g. between close friends, colleagues and others as not every user wanted to grant all contacts the same access to its profiles. But exactly this was the case in the Friendster environment. As a consequence, the dropout rates increased. A further related reason was an increasing abuse of the network by spammers and "Fakesters" that exploited the network functionality for advertising and spam (Boyd 2007). This leads to social collisions and decreasing trust of users in the providers. Recent scandals on large-scale surveillance of Web activities contribute drastically to decrease trust on wider societal level.

\subsection{Considerations on the public and private spheres}

With the occurrence of SNS, questions on the relationship between the public and the private sphere reappeared. According to Habermas' (1989) classical work, the public sphere represents an essential part of deliberative democracy that serves the function to intermediate between citizens and political decision makers. From a more general view, the public sphere is "an open field of communicative exchange. It is made up of communication flows and discourses which allow for the diffusion of intersubjective meaning and understanding" (Trenz 2008, p. 2). With its inherent deliberative quality it is to be understood not merely as some form of public communication but as element that transforms public communication into public opinion (Frazer 2007; Trenz 2008).

The development of this deliberative quality is connected with the private sphere, i.e. those spaces and domains where individuals have the ability to be and act free and without interference from others. Hence, domains where privacy is factual and people are able "to engage in worthwhile activities that they would otherwise find difficult or impossible" (Solove 2006, p. 484). In this respect, the relation between the private and the public sphere is complementary: individuals develop their opinions in their private sphere; and, by communicating and interacting with other individuals the public sphere takes shape (cf. Habermas 1989). It is vital that both spheres have enough open space to emerge and develop where individuals can meet, share thoughts, discuss their opinions, exchange ideas etc. without interference. Otherwise, if such space for open, communicative exchange is limited, the deliberative quality and transformative capacity as essential parts of democratic will formation might diminish. In the analogue world, different kinds of public spaces provide room for both spheres to converge. But where are SNS environments to be located in the interplay between the public and the private sphere?

At first glance, SNS environments appear as public spaces, i.e. "non-domestic physical sites that are distinguished by their relative accessibility [...]" (Humphreys 2010, p. 2). For Boyd (2007b), SNS can be seen similar as "mediated publics" and "yet another form of public space". However, there are significant differences between SNS and traditional public spaces: As SNS access usually demands user authentication, it represents a specific space on the Internet, which is to some extent separated from others - a form of semi-public space. One distinguishing factor is the visibility of interactions: Considering a common public square in the analogue world, the behaviour, movements and interactions of individuals are generally visible to others nearby; however, there is usually no systematic monitoring of interactions and communication content. Thus, this visibility is rather volatile and with different varying levels of privacy. In an SNS environment, social relations and interactions including the content are explicitly observable (and observed). This observability is given because the relations between personal (friends, contacts, etc.) and non-personal entities (interests, content used, shared, linked, liked, produced, etc.) are part of the information processed (Strauß/Nentwich 2013).

As "there has never been a single authoritative public sphere in which citizens formed a public opinion or a common collective identity" (Nanz 2007, p. 19), the public sphere should not be (mis-)understood as a single space of public deliberation and discourse, but as a "communicative network where different publics partially overlap" (ibid). In this regard, SNS also provide a sparkling example for a novel, digital 
representation of the public sphere. It is hardly applicable to analyse whether the vast amount of heterogeneous partial publics being active in SNS environments mirrors and influences public communication in general. However, the impact of activism in SNS for instance on public discourse is evident at least since the Arab Spring revolutions. In the last few years, social media began to grow wider into traditional mass media and visibly contributes to public discourse.

\subsection{SNS and political participation}

The benefits of SNS are manifold as their characteristics provide a variety of options to strengthen relations between individuals as well as institutions. The assumed and to some extent observed potential for democratic processes includes for instance political action, campaigning, participation, establishing links between public sector and civil society and foster the relationship between citizens and government etc. (cf. CLG 2008).

There are several studies on the effects of ICT and social media for political participation in the field of eparticipation (OECD 2007; Levine 2002; Macintosh 2003; Baringhorst 2009; Lindner et al. 2011). Assumed effects are inter alia increasing political engagement due to the ICT-induced networking culture, enhanced social capital building and stimulation of active citizenship. For instance, Kann et al. (2007) postulate that Internet communication created a new culture of political participation by promoting values conducive to democracy, such as citizen involvement, openness, exposure to political information and ideas and facilitating political mobilization and campaigning. Social media inter alia was used extensively for political campaigning during the US elections in 2008 (cf. Smith 2009). SNS in general reflect the societal need to communicate and socialize with other individuals. Their modalities correspond to the need to share lively experiences and connect with others. In this regard, SNS usage can be seen as "a way of sustaining communication and continued sharing of experience and learning" (CLG 2008, p. 6). Blogging, citizen journalism, publishing critical videos on public events or politics or similar contribute to public discourse as different opinions may stimulate interest in debate (OECD 2007).

However, while some evidence exists on such effects in specific cases, the related expectations have to be relativized as the

"intended effects of e-participation can hardly be obtained by relying on the technical means. A common fallacy is that the deployment of ICT for participatory approaches will directly lead to, e.g., more transparency, increased engagement, community empowerment and, as a consequence, to fostering the quality of deliberation on political issues. (...) [T]here are several crucial determinants which are often neglected. On the technical and organisational level, ICT usage entails high requirements regarding organisation, structure, knowledge etc. for initiators as well as for participants; the employed technology needs to be embedded in the participation process in an appropriate way, i.e., the tools need to be suitable for the objectives of the participation and need to be in accordance with the organisational structure of the process. The mere offering of e-participation without convincing structural adaptations, provisions for integration into the political process and transparent feedback cannot lead to higher and better balanced levels of involvement and contribution quality. Besides this demand for an appropriate techno-organisational setting, the process as a whole needs to be well-structured and made public to its audience, i.e., the actors of the public sphere." (Lindner et al. 2011, p. 111).

These arguments underline that political participation is not reducible to technical means. Hence, the expectations that ICTs and social media improve democratic processes in general are mostly overestimated as having the opportunity to publish does not automatically imply that your voice will be heard in the public sphere (Lindner 2007).

The expectation that a general SNS such as Facebook entails positive effects on civic engagement and democracy is likely to be misleading as the modes and mechanisms of democracy are complex and not reducible to the online world. A major reason is that a general network per se has no such intended 
context (such as stimulating participation) but in its broadest sense simply connecting people. While this surely is a sine qua non for participation it is not a sufficient factor for determining participation.

This does not neglect the mobilizing power of social media. The potential of SNS to improve interaction and instant communication and exchange among individuals and interest groups is evident in many respects. A prominent example is given by the Arab Spring revolutions, where SNS where important tools to support activists and had significant political impact. Social media channels were successfully used by civil society to organize and mobilize democratic movements against the governing regimes in the regions. While the political will to engage in these movements is bound to the particular individual and thus no result of ICT, these channels can catalyse existing political engagement by stimulating mobilization. The networking structure of SNS, its high flexibility and the related leverage-effects provided ideal means to support activists in organising and coordinating protest movements and raise their outreach: in 2011, „millions of Facebook and Twitter users in Tunesia and Egypt formed a social grid massively parallel that sustained the revolutionary waves in Tunis and Cairo's main streets and suburbs as well as in the secondary towns of the countryside" (Benkirane 2012). The networking nature of SNS made it possible not only to organize, but also to mutually learn as protesters shared their experiences, spread news, sympathy and support with others over the networks. These learning effects in real time also contributed to the success of activists (Skinner 2012).

In this regard, social media channels served as catalysts: they ",accelerated local reactions, synchronized different levels and intensities of uprisings and permitted the coverage of events through real-time footage directed to global opinion" (ibid). However, the same technologies that supported the democratization process were used for control and repression of citizens by the authoritarian governments of the region.

Hence, the role of social media for political participation is to some extent an ambivalent one. "Social networks and new media can transform information sharing into creative ways of knowledge production. But they can also be used for control and manipulation of citizens" (ibid). It depends not least on the political-administrative system or regime and the cultural context of SNS usage. As Dahlgren (2013) puts it: "Democracy will not be saved by media technologies; social media can make an important difference in this regard, but they can also function to exacerbate democracy's difficulties. Ultimately only citizens can revitalise and extend democracy; that is our only realistic option". While the role of social media for political participation is ambivalent it bears manifold potential for knowledge production as described in the next section.

\subsection{SNS and knowledge production}

To provide an advanced and encompassing platform for easy and informal communication in various forms is obviously the prime functionality of SNS. However, many of the tools available in SNS may also serve other purposes, in particular supporting the production of new knowledge. In this sub-section we distinguish between the content-related side, i.e. what role SNS may play in producing knowledge, and the business-related side, i.e. in which ways SNS may contribute to the (knowledge) economy, besides refinancing the operation of the SNS.

\section{The content side}

A non-linear model of how knowledge is produced distinguishes between four interlinked and overlapping areas (Nentwich 2003, p. 23ff.): (1) the institutional settings, i.e. the framework in which knowledge production takes place, including the technical equipment, (2) knowledge production in the narrow sense, i.e. information gathering, data production, data-processing and -analysis, data management, (3) knowledge processing, i.e. knowledge representation, discourse, cooperation and evaluation, and finally (4) knowledge distribution, i.e. publication, teaching, and implementation (see Figure 8). In all four areas information technology in general, and new social media, in particular SNS, 
have an impact. While this has been shown with regard to activities in the field of science and research under the label of "cyberscience" (Nentwich/König 2012; Nentwich 2003), there can be no doubt that this could be shown for other areas of knowledge production as well, for instance in the software industry or in the consultancy business.

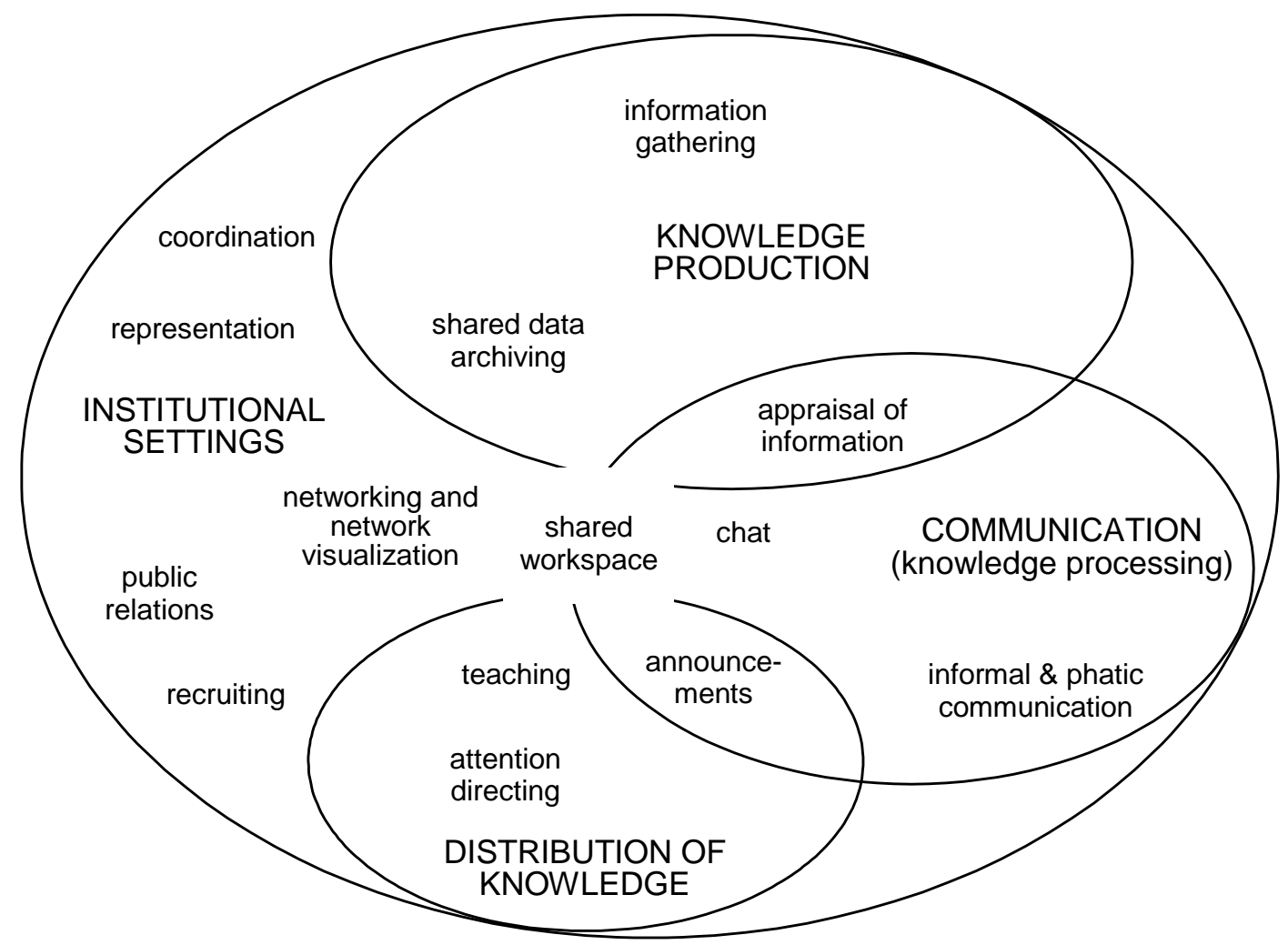

Figure 8: Knowledge production

Source: Nentwich 2003, 24

When it comes to the specific role of SNS in knowledge production, the core observation is that the various functions of directing attention (from the "Like" button to user ratings, from user tagging to automated recommender systems) may be helpful in the process of acquiring information, particularly with regard to documents, literature, news items and the like. In addition some SNS offer groupwarelike collaboration tools like shared data or file archives or collaborative text editors, which potentially help working groups in their data management, i.e. administering their files etc. Probably even more important than the information acquisition phase is how the knowledge is processed, i.e. how it is elaborated, refined, tested, and evaluated it through communication and discourse in expert circles (and beyond). The various channels offered by SNS enable quick and informal, synchronous and asynchronous ways of exchanging thoughts about the new knowledge in nuce. It is this easiness of communication within SNS that offers the potential of a faster turn-around of knowledge.

An important asset of SNS as compared to previous and parallel tools supporting knowledge production is its potential to include not only many more, but also a greater variety of actors, data-providers, and experts in the process. A particular strength of SNS is their potentially wide user base. Whatever the specialty, whatever the topic, it is likely that the huge networks represented in SNS will come up with one or more individuals that have the right expertise, practical knowledge or represent a needed point of view. Hence SNS, as a specific digital infrastructure, may play a role in the so-called crowdsourcing. 
Crowdsourcing is usually defined ${ }^{8}$ as the practice of obtaining knowledge (services, ideas, or content) by soliciting contributions from a large group of people, and especially from an online community, rather than from traditional employees or suppliers. Wikipedia, a very important producer of a knowledge resource, is the most prominent example in that respect and can be labeled a proto-SNS (as regular users have their individual profiles and communicate mainly through the Wikipedia-specific internal communication channels).

All these are potentials only, though. As we observe only the early stage of the diffusion of SNS and associated new modes of knowledge production, it is too early to draw any definite conclusions.

\section{The business side}

The so-called knowledge economy (cf. Drucker 1969) is characterized by the use of knowledge to create goods and services, whereby technology plays an important role. SNS represent technologies that fit into this framing. The vast amounts of content users share and produce becomes widely available across the SNS environment. This content provides high value for different kinds of business models. In this respect, SNS are both in itself a business model in this economy and enable further economic activities.

The large SNS, such as Facebook are, so far, a viable business model, successful even at the stock markets. SNS differ, however, with regard to their sources of funding. Nentwich/König (2012) observe seven models, which are not mutually exclusive and are often combined:

- User-specific advertisement: The substantial data shared by the users gives a comprehensive picture of the interests of persons or groups. This makes them commercially attractive as it is possible to place personalized advertisement and gather valuable knowledge about markets. In order to attract as many people as possible, the network is usually for free in this model, but users have to allow analyzing their data. Therefore this has been labeled the "service-for-profile model" (Elmer 2004; Rogers 2009), as applied e.g. in Facebook, but also in other platforms, such as Google's. In a variant of this model the user data acquired inside the SNS is not only used for user-specific advertisement inside that SNS, but may become a separate good to be sold to other providers.

- Scattered advertisement: Apart from personalized advertisement, also less targeted, general advertisement may be presented, for example on start pages (e.g. StudiVZ).

- Fees: Some SNS charge fees for premium functions (e.g. Xing), such as specific services, or enriched profiles for commercial users. Some of the job exchange services are free for members, but not for those advertising jobs (e.g. Xing).

- Subsidies: Some SNS are financed via public money in the form of project grants (examples can be found in the science-specific SNS, such as Vivo, research.iversity, ScholarZ.net).

- Donations: As the commercial models have often been criticized -in particular with regard to data protection and privacy issues of the service-for-profile model-some users are prepared to donate in favor of non-commercial offers. One trailblazer is Diaspora9, which is being developed as a future competitor of Facebook. In order to raise donations, the Internet is used in the form of the socalled crowdfunding.

- Out of the marketing budget: There are cases where SNS are seen as part of the public relations strategy of an institution or enterprise and is therefore funded from the marketing budget (e.g. NatureNetworks).

- "Start-up“: Frequently, SNS are set up as start-up companies, which invest first in the infrastructure and in collecting members (e.g. ResearchGate, funded by Harvard University). Only when the site

\footnotetext{
${ }^{8}$ http://www.merriam-webster.com/dictionary/crowdsourcing.

${ }^{9}$ http://joindiaspora.com.
} 
has a large number of users - the SNS' capital - it may generate earnings. Such start-ups may later be bought by large companies (e.g. Mendeley, bought by Elsevier in Spring 2013).

Crowdsourcing is not only an interesting way of distributing the work among volunteers, but SNS may play an important role in mediating demand and offer for outsourced collaboration between free producers, often labeled "edupunks", and companies as an example of new technology-based organizational formats (Al-Ani 2013). Other types of crowdsourcing often associated with SNS are crowdfunding activities where projects get funded by a multitude of people contributing only a small amount. Recruiting contributors via a large SNS user base may be quite successful. 


\section{PRIVACY IMPLICATIONS AND CHALLENGES AHEAD}

In general, privacy is among the heavily contested domains of the contemporary information society. The widespread diffusion and usage of SNS, and social media in general, highlights the increasing dynamics of the on-going societal transformation where analogue and digital environments more and more converge. This lead to new challenges for the effective protection of personal information - as privacy scholars stress since several years. SNS environments are a significant part in this privacy "puzzle". This section sheds some light on the major pieces in this debate.

\subsection{Information disclosure and informational self-determination}

Despite of the manifold different usage contexts, sharing personal data and information play an essential role in the very design of SNS as every form of social interaction needs a certain amount of information about the parties involved. On the one hand, the wide range of new possibilities for sharing and creating content supports community building and collective actions; on the other hand, it further stresses informational privacy and the users controllability over his/her personal information in several ways (and not least due to complex modes of data processing that refer to distributed computing in the cloud). Or in other words: the distinction between personal information and user content diminishes further within social networks.

Thus, privacy, trust, and proper handling of personal information are crucial aspects of SNS. In this regard there are potential conflicts between users' intentions to share personal information and the way this information is used by the SNS (e.g. behavioural targeting and processing of user data for commercial interests). These issues are not least affected by the interplay between privacy awareness, different usage patterns and features supported by the SNS.

The fact, that users share vast amounts of personal information in SNS is evident. A number of studies exist to explore what information users reveal (cf. Acquisti/Gross 2006; Barnes 2006; Fuchs 2009; Leenes 2010). Lack of privacy awareness among SNS users is surely an important issue in this regard. However, the problem seems to be more complex because disclosing information does not necessarily imply that SNS users do not care about their personal privacy. On the contrary, users who are well aware of the privacy problems of their SNS usage are seemingly not a minority. According to a critical study exploring the perceptions of SNS users on advantages and disadvantages of SNS, for the majority of the respondents $(55.7 \%)$, a main threat is "political, economic, or personal surveillance as a result of data abuse, data forwarding, or a lack of data protection"; for $23 \%$ the disclosure of personal affairs is problematic; about $8 \%$ see the danger of job-related disadvantages if current or potential employers access profiles, $6.6 \%$ are concerned about advertising or spam. At the same time, respondents named maintaining existing contacts (59.1\%) and establishing new contacts $(29.8 \%)$ as the main benefits of SNS (Fuchs 2009). Hence, the majority of the participants seem to perceive that the advantages of SNS are somewhat coupled with risks regarding surveillance and loss of privacy.

A special Eurobarometer survey (EC 2011) displays similar results. Figure 9 below shows what kinds of information European citizens perceive as personal and what they have already disclosed via online social media ${ }^{10}$ :

\footnotetext{
10 The chart is based on the responses to the questions "Which of the following types of information and data that are related to you do you consider as personal?" and "Thinking of your usage of social media and sharing sites, which of the following types of information have you already disclosed (when you registered, or simply when using these websites)?" from the special Eurobarometer 359 (EC 2011).
} 


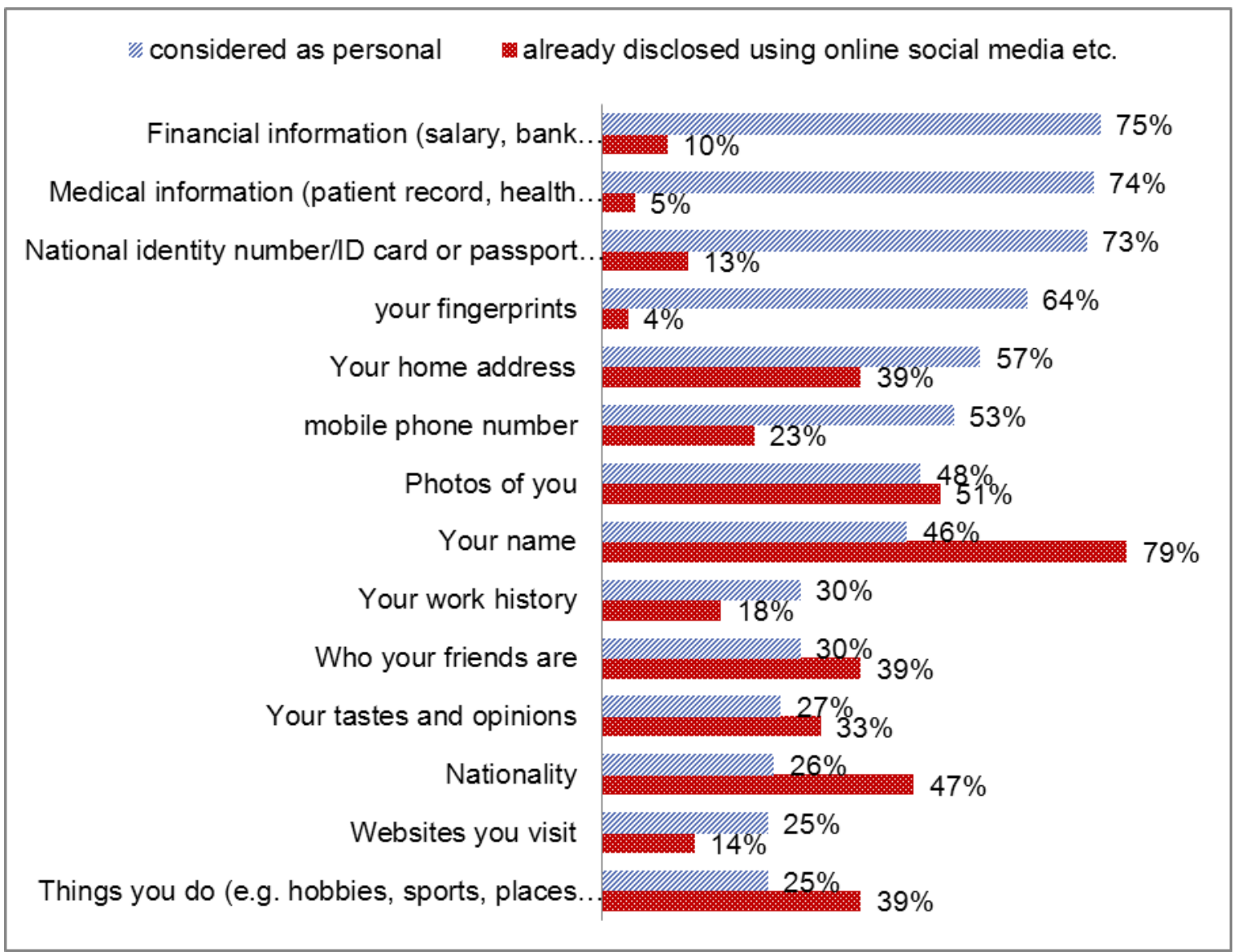

Figure 9: Perceptions of personal information and amount of disclosure due to online social media usage (Source: EC 2011)

About $50 \%$ of the European citizens have the perception that disclosing personal information is hardly avoidable on the Internet. As Figure 9 demonstrates, social media has an essential share in this regard. Among SNS users, the two main reasons for disclosure are to gain access to a service $(61 \%)$ and to connect with others (52\%). Also half of the SNS users were already in a situation where they had to reveal more personal information than service usage would require. Over $70 \%$ are (very or fairly) concerned about such cases. More than $50 \%$ of the internet users are concerned about profiling activities although the question was linked to positive effects such as gaining free services. One could argue that users need to be more aware of their own responsibility for handling personal information. Awarenessraising in this regard is without any doubt an important issue. However, this does not seem to be a sufficient measure: three-quarters of the European Internet users seem to be somewhat aware of this and at the same time see a demand for more responsible treatment of their information by online sites. Among SNS users, 75 \% perceive a need for more control of their personal information (EC 2011). Hence, there seems to be awareness of privacy problems related to SNS usage, but users perceive a lack of control over their personal information flows.

This refers to the concept of informational self-determination as introduced by the German Federal Constitutional Court in 198311. Informational self-determination defines a state in which the individual affected by information processing is aware of this process, e.g. what personal information is stored for

11 Judgment of the First Senate from 15 December 1983, 1 BvR 209/83 et al. - Population Census, BVerfGE 65, 1. 
which purpose and is also capable of controlling how it is processed. There are two main aspects of ISD that can be distinguished:

- Knowledge about the context of information processing and

- $\quad$ Control over that context, i.e. the personal information flows

This ties in with the concept of purpose limitation, which is among the core privacy requirements. The introduction of informational self-determination had high impact on European data protection legislation and represents a major issue of contemporary privacy protection.

\section{Complexity of privacy settings and user preferences}

SNS provide a certain amount of control over personal information. Users can customize their settings based on their preferences and to some extent determine which information should be visible and accessible to others. While this sounds in line with the concept of informational self-determination, there are many critical aspects in this regard. The way privacy is handled in SNS environments seems to have shifted towards a "disclosure-by-default" paradigm (Strauß/Nentwich 2013) Facebook's privacy policy12 of 2010 underlines this shift:

"When you connect with an application or website it will have access to General Information about you. The term General Information includes your and your friends' names, profile pictures, gender, user IDs, connections, and any content shared using the Everyone privacy setting. [...] The default privacy setting for certain types of information you post on Facebook is set to 'everyone'. [...] Because it takes two to connect, your privacy settings only control who can see the connection on your profile page. If you are uncomfortable with the connection being publicly available, you should consider removing (or not making) the connection."13

Figure $10^{14}$ below visualizes how Facebook's default privacy settings changed over time:

\footnotetext{
12 Recently in 2013, Facebook again changed its settings, According to the New York Times, “Facebook's new policies make clear that users are required to grant the company wide permission to use their personal information in advertising as a condition of using the service."

http://www.nytimes.com/2013/09/12/technology/personaltech/ftc-looking-into-facebook-privacy-policy.html.

${ }^{13}$ http:// www.yalelawtech.org/control-privacy-technology/evolution-of-facebook-privacy.

14 This visualization is only an extract and does not cover the full range of personal information disclosed.
} 


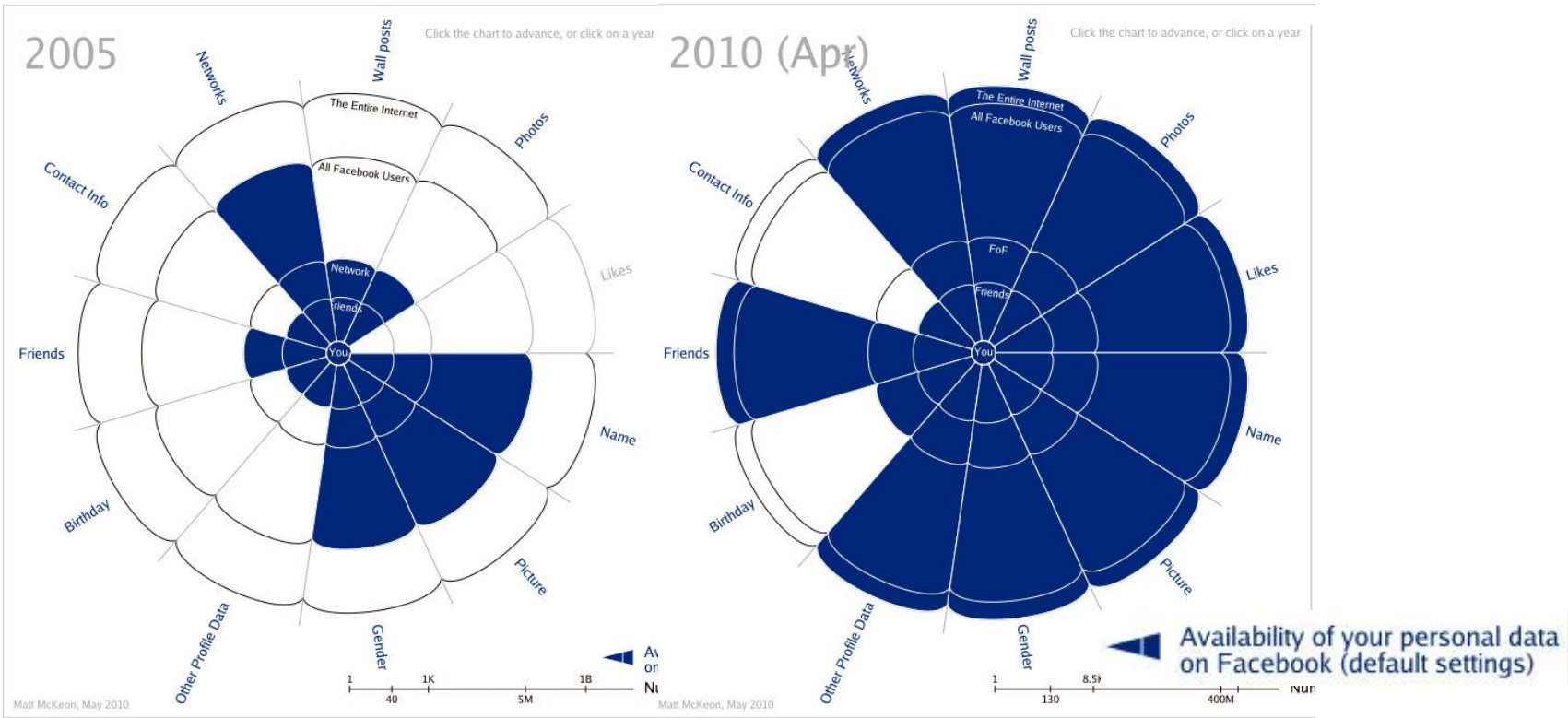

Figure 10: Facebook's privacy setting over time

Source: Matt McKeon 2010 http:/ / mattmckeon.com/facebook-privacy

In 2005, availability to most information was limited at least to the list of contacts and only some to members. As Figure 10 shows, the default settings have significantly changed until 2010. What was once protected by the standard privacy configuration is now accessible by default. SNS users who keep this standard setting disclose for instance practically all information in their profiles, their contacts, their photos, and their preferences (e.g. "likes"). While at least the widest circle of disclosure was limited to members, this information is now visible not merely to friends or all SNS members, but also to entities in the World Wide Web outside the SNS environment.

One could argue that users can at least change their privacy settings and do not have to keep the default settings. However, this argument has limits: the complexity of the settings complicates the users' ability to customize their preferences. Furthermore, the amount of privacy-awareness differs widely among users. Surely a complete lack of privacy settings would worsen the problem. However, the options available to reduce information disclosure such as reducing profile visibility are rather "a quick fix (...) than a systematic approach to protecting privacy" (Debatin/Lovejoy 2009, p. 103).

Facebook's privacy policy also raised concerns of the European Commission. In 2009, the Commission released a set of principles for safer social networking recommending inter alia to "[e]nable and encourage users to employ a safe approach to personal information and privacy" (EC 2009). However, these principles were limited to enhance protection of minors. The Article 29 Working Party put more emphasis on the importance of privacy settings: "SNS should offer privacy-friendly default settings which allow users to freely and specifically consent to any access to their profile's content that is beyond their self-selected contacts in order to reduce the risk of unlawful processing by third parties" (Article 29 Data Protection Working Party 2009). As Facebook changed its settings in December 2009 (a few days after the release of the Working Party's opinion), in a letter to Facebook the Working Party underlined its opinion and called the fundamental changes at the cost of users privacy "unacceptable" (Article 29 Data Protection Working Party 2010).

This issue underlines the problem of fluid privacy settings. As the default settings changed significantly over time and SNS rapidly introduce new features, this problem is further exacerbated (e.g. in some cases, the users' settings can be undermined by the introduction of new settings or features). A recent study reveals that although users seem to be more aware of customizing their privacy settings, confusing 
changes of these lead to unintended disclosure. ${ }^{15}$ Furthermore, in many cases, the terms of use allow the SNS to process the users' personal data including third parties. In addition, most third party applications and services have specific terms of use. Some require the users' consent to process personal data, others automatically collect these data. As services are embedded, data from these also flow back into the SNS environment.

Even if a user customizes her profile according to her very own perception of privacy, problems remain as: due to the usage policy of most SNS (e.g. Facebook), users give consent on the disclosure of their personal information. Finally, despite of the privacy settings, the SNS serves as centralized repository holding detailed information about the individual user. ${ }^{16}$

This information is also attractive for a variety of observers in the public and the private sector. SNS provide ideal environments for large-scale profiling which "builds on combining two strands of information to create an expectation of individual users' future preferences, wishes and behaviours" (Van der Berg 2011, p. 187). These two streams of information are "the totality of past behaviours and choices of a single individual" and "the collective behaviours of a large group of people, with respect to one single choice or purchase" (ibid, p. 188). Many business models ground on these data e.g. social marketing, behavioural advertising or specific monitoring of social media in order to predict new trends. An example is "Mass Relevance" which claims to aggregate SNS content in real-time. ${ }^{17}$ In the public sector, similar activities occur under the term "predictive policing" with the hope to be able to predict crimes; large-scale surveillance of Internet communication by security authorities and intelligence agencies is heavily evident since the revelations of the PRISM and Tempora projects. ${ }^{18}$

\section{Lessons from PRISM}

One major reason for the rapid growth and success of SNS can be traced to the fact that they correspond to a societal need to communicate and share thoughts, ideas etc. It sounds obvious that users of SNS should not be punished for their openness and willingness to share parts of their lives with others. However, against the background of the recent surveillance scandals, exactly this seems to be the case. Communication, information exchange and collaboration are important societal achievements. If these achievements are undermined and exploited, this may cause enormous harm to society as a whole, because neither a loss of trust in private companies nor in the political-administrative system is easily reparable. ${ }^{19}$ PRISM and Tempora drastically highlight the urgent need for a reconsideration and revitalization of privacy and scrutiny as public values in contemporary society (cf. Strauß 2014 forthcoming). The collateral damage for society done by such mass surveillance and user exploitation in SNS and beyond is yet unforeseeable. Trust is among the core aspects of democratic societies. It is also a mutual concept that cannot function in a unidirectional way. In this regard, the basic idea of SNS environments can contribute to foster mutual learning in a variety of ways. As regards privacy, users yet have to learn the hard way that their personal information is open to abuse and infringements by a

\footnotetext{
15 http:/ / allfacebook.com/carnegie-mellon-facebook-privacy-study_b112298.

${ }^{16}$ In the case of Facebook these and other privacy problems are currently part of law suit going on in Europe, known under the label "Europe vs. Facebook". The related platform http://www.europe-v-facebook.org/EN/en.html provides detailed information on what data is collected and processed by Facebook (http://www.europe-vfacebook.org/EN/Data_Pool/data_pool.html).

${ }^{17}$ For further examples see http://www.insidefacebook.com/category/social-media-monitoring/

$18 \quad$ Cf. $\quad$ http://www.zdnet.com/prism-heres-how-the-nsa-wiretapped-the-internet-7000016565/ http://www.guardian.co.uk/uk/2013/jun/21/gchq-cables-secret-world-communications-nsa.

${ }^{19}$ Recent studies show loss of trust in private and public institutions due to the PRISM scandal. E.g. user drop-out in Facebook http://www.dailymail.co.uk/sciencetech/article-2423713/Facebook-users-committing-virtual-identitysuicide-quitting-site-droves-privacy-addiction-fears.html, and lack of trust among internet users in government institutions http://www.bitkom.org/de/presse/8477_76831.aspx.
} 
multitude of actors. Before PRISM, in public opinion this was often "merely" a business issue. However, now we may assume that privacy and surveillance are affecting society as a whole.

\subsection{Personal vs. non-personal data and identifiable information}

According to the European Data Protection Directive $(95 / 46 / \mathrm{EC})^{20}$, personal data represents information that relates to an identified or identifiable natural person (or data subject). In case of anonymous or anonymised information, i.e. information that does enable identification of the data subject, protection principles do not apply. At first glance, this is reasonable. However, the role and meaning of identifiable information has significantly changed. A possible distinction of identifiable information is between person-specific data referring directly to one's identity (e.g. name, date of birth, etc.) and explicitly entered by a user; and technology-specific data referring to one's technical devices (e.g. IP-, or MACaddress, web browser identifiers, etc.) processed during a user-session without direct user interaction (Strauß 2011). In general, the variety of data collected and processed can be distinguished in explicit data, i.e. information directly related to service usage which a user uploads to a digital environment (e.g. profile details, interests, photos, etc.), and implicit data, i.e., information that is processed automatically in the system without direct involvement of the individual (e.g. browser data, interactions, content, web sites visited, profiling, etc.). Whether processed information is personal or non-personal is increasingly difficult to determine. Contemporary and emerging information processing, particularly as regards SNS and other networked environments, vividly demonstrate that the distinction between personal and nonpersonal data diminishes. This heavily strains "unlinkability", which is a crucial requirement for the technical implementation of informational self-determination. Unlinkability prevents from privacyinfringing linkage of separated information, i.e. that different contexts stored in different repositories become merged into one central profile. This linkage is possible due to unique identifiers. The effectiveness of unlinkability suffers from increasing options to create identifiers. In digital environments, every form of interaction creates a certain amount of traces. This is obvious in the case of personal data, but also non-personal data are traceable leading to one's identity. With increasing amounts of data linkable to a person his or her "identity shadow" (Strauß 2011) expands, entailing, new options to re-identify an individual by gathering quasi-identifiers from these data. As "context is everything" (Leenes 2010) in an SNS environment that processes vast amounts of personal information with rich context information, there are several options to apply de-anonymisation techniques (cf. Wondracek et al. 2010). These aspects cannot be protected by current SNS privacy settings. A further aspect is information disclosed to other contacts that also undermine privacy settings: "leaking graph information enables transitive loss: 'insecure friends' profiles can be correlated to a user with a private profile" (Bonneau et al. 2009, p. 6). Hence, even if information would be protected by the privacy settings (which is not the case as outlined), the effectiveness of this protection would depend also on the settings of the contacts a user is related to.

The increasing relevance of social plugins and embedded services (see Section 3.3) feeds the array of context information and further undermines informational self-determination. Users mostly have to give consent if they want to use an app. Furthermore, those third parties providing the services extract and gather personal information from the SNS to analyse user behaviour (e.g. for targeted advertising), also without the users' consent. ${ }^{21}$ Also this practice of data gathering is manifold as vice versa the SNS itself

\footnotetext{
20 Directive 95/46/EC of the European Parliament and of the Council of 24 October 1995 on the protection of individuals with regard to the processing of personal data and on the free movement of such data http://eurlex.europa.eu/LexUriServ/LexUriServ.do?uri=CELEX:31995L0046:EN:HTML At current stage, the reform process for a new European Privacy Framework is still going on.

${ }^{21}$ E.g. popular apps and games such as Farmville and others undermine the privacy settings and submit data to advertisers. According to the Wallstreet Journal, Facebook IDs of users were sent to at least 25 different companies. Wallstreet Journal Oct. 172010

http://online.wsj.com/article/SB10001424052702304772804575558484075236968.html
} 
absorbs data also from the outside Web and traces user behaviour also in contexts that are usually not related to SNS usage. With the social graph and developments towards "social search", the mapping of personal relations extends towards a mapping of user information, preferences, behaviour, activities, social relationships, etc. In this regard, SNS dig deep in the identity and behavioural patterns of users. The already existing conflict between users intentions to share information, for instance with a view to socialising, and how this information is treated by the SNS intensifies. A certain amount of user control is essential for the effectiveness of privacy protection, not least regarding this "privacy-sociality tradeoff" (Leenes 2010). However, all these (de-) and (re-)contextualisation aspects elaborated above make informational self-determination a rather tricky task to cope with.

\subsection{Seven types of privacy}

A common notion of privacy is the definition of Warren and Brandeis (1890) as "the right to be left alone". Westin (1967)points out the role of information and defines privacy as "the claim of individuals, groups or institutions to determine for themselves, when, how and to what extent information is communicated to others". This classical definition points out that privacy is closely linked to information processing.

As outlined in the previous sections, essential aspects that complicate improving informational selfdetermination in general is the particular nature of digital information shaped by ICT and the way it is processed. This dynamic nature often hampers addressing privacy impacts of a particular technology systematically as privacy intrusions also become more dynamic. As a consequence, privacy is to be understood as a multidimensional concept consisting of different types and dimensions. As Clarke (2006)distinguishes four major types: privacy of the person, privacy of personal behaviour, privacy of social communications and privacy of personal data. Finn et al. (2013) propose an extended taxonomy of "seven types of privacy" by complementing additional dimensions to Clarke's approach, privacy of

- the person encompasses the protection of body functions and characteristics, such as biometrics or genetic codes;

- behaviour and action addresses the "ability to behave in public, semi-public or one's private space without having actions monitored or controlled by others"; this involves "sensitive issues such as sexual preferences and habits, political activities and religious practices" (ibid);

- communication includes the ability to communicate freely via different media and without interception including the avoidance of different forms of wiretapping and surveillance of communication;

- data and image addresses the protection of data from automatic disclosure to other individuals and organizations; individuals should have "a substantial degree of control" over their data and its usage (Clarke 2006); image is a particular "form of personal data can be mined for biometric data and used to identify, monitor and/or track individuals as they move about public or semipublic space" (ibid);

- thoughts and feelings involves an individuals' freedom to think and feel whatever he/she likes to without restriction; this type differs from behaviour as thoughts do not necessarily translate into behaviour;

- location and space encompasses one's right to move free from interference in private, public or semi-public space without being identified, tracked or monitored;

- association (including group privacy) addresses one's right to associate with whomever he/she wants without being monitored. This also includes groupings or profiles over which one has no control (e.g. involvement in discussion groups) (ibid).

This taxonomy allows to grasp more systematically to what extend a technology affects privacy. Table 3 below shows a general mapping on which of these types are affected by SNS: 
Table 3: Privacy types and SNS usage

\begin{tabular}{lcc}
\hline Privacy of ... & $\begin{array}{c}\text { Common SNS } \\
\text { usage }\end{array}$ & $\begin{array}{c}\text { Emerging SNS } \\
\text { usage }\end{array}$ \\
\hline the person & $(X)$ & $X$ \\
behaviour and action & $X$ & $X$ \\
communication & $X$ & $X$ \\
data and image & $(X)$ & $X$ \\
thoughts and feelings & & $X$ \\
location and space & $X$ & $X$ \\
association & & $X$ \\
(incl. group privacy) & & \\
\hline
\end{tabular}

Source: Strauß/Nentwich (2013)

Table 3 compares common usage of contemporary SNS and emerging SNS usage, which refers to the rapid development of social networks and upcoming trends. The main types currently affected are privacy of communication, data and image as well as privacy of association. As communication and interaction is at its very core, SNS gather extensive arrays of information in this regard; these and other data are accessible and per default disclosed to others, including images and photos; privacy of association also affected as the list of contacts is visible. Furthermore, the related profiles can undermine the privacy of other contacts. As the relations and interactions in SNS include personal as well as nonpersonal entities (i.e. content) related information this gives some insights into behaviour and action (e.g. contributions in discussions, postings, interests, etc.) and even thoughts and feelings: Some SNS features try to seduce users by revealing information in this regard. For instance in Facebook, users are asked "How are you feeling?", "What are you doing?" and similar. Hence, to some extent, also these privacy types are affected at present.

The on-going diffusion and further expansion of the SNS universe makes it likely that privacy impacts increase affecting additional types of privacy. Three main trends can be identified in this regard (Strauß/Nentwich 2013):

1) Social plugins and the social graph aiming at gaining deeper insights into users' identity and behavioural patterns and perceptions also outside the SNS environment.

2) Face recognition and biometrics, which develop quickly and are beginning to reach into SNS contexts (cf. Power 2011) affect the privacy of the person. For instance, Facebook supports photo tagging to link persons and their profiles; Google is the owner of patent for "facial recognition with social network aiding" 22 ; these developments link the appearance of a person in both the physical and the virtual world.

3) Mobile social media usage significantly increases: the amount of mobile data processed doubled from 2011 to 2012 (Ericsson 2012); with location-based services and mobile apps, access to SNS via mobile devices (such as smart phones, tablet PCs, etc.) becomes more attractive. According to ComScore (2012), mobile SNS access rates increased over 70 \% from 2010 to 2011. Hence, also privacy of location and space becomes affected further.

${ }^{22}$ https://www.informationweek.com/internet/google/google-seeks-social-networking-face-reco/229218484 


\subsection{Privacy-by-design vs. disclosure-by-default}

As highlighted in the previous sections, one of the core privacy problems of SNS is the prevailing paradigm to disclose information by default which pervades SNS environments. Related is the second core problem that identifiable information increases due to diminishing boundaries between personal and non-personal data. Thus, in order to cope with current and upcoming privacy challenges, a shift of this paradigm is necessary towards privacy-by-design and privacy-by-default schemes. As the term implies, privacy-by-design encompasses approaches to embed privacy and data protection into the very design, operation and management of technologies. Realizing privacy-by-design grounds on seven foundational principles (Cavoukian 2009):

- Proactive not reactive; preventative not remedial, i.e. privacy is to be proactively implemented before, not after a risk or breach occurs.

- Privacy as the default setting, i.e. privacy as built-in feature without requiring users action to customize settings.

- Privacy embedded into design, i.e. as integral part of systems and practices without diminishing functionality

- Full functionality - positive-sum, not zero-sum, i.e. without constructed trade-offs such as privacy vs. security but embracing multiple functionalities

- End-to-end life-cycle protection, i.e. a "cradle-to-grave lifecycle management of personal information" beginning already with the first information processed including a deletion at the end of the process

- Visibility and transparency, i.e. data processing needs to be understandable and controllable to scrutinize proper handling of information

- User-centricity, respect for user privacy, i.e. incorporating the user as a central part of the system and empowering their active role in privacy protection.

These principles are essential guidelines to improve privacy and data protection related to technology. Islam and Iannella (2012) analysed the privacy-friendly SNS Diaspora regarding its implementation of these principles. Diaspora ${ }^{23}$ is a privacy-aware, decentralized, distributed social network that aims to replace centralized SNS that failed in protecting privacy. Its architecture is thus different from common SNS: a core aspect is that users should have more control and thus the network is decentralized consisting of so-called "pods", i.e. private servers where user accounts (seeds) are hosted. Users can store and control their data via these pods. They can choose whether to manage their own servers or use a public pod. As the software is open source and users can run their own servers, the system provide high amount of user control. Islam and Iannella (2012) found that some principles are well addressed, in particular that the network is proactive, as it provides flexible options for users to control their data; and that visibility and transparency are high as the system is open source and users can setup their own SNS. While privacy-by-default is implemented, data security seems to be in the first place, hence full functionality is only partially given. As security is a dominant issue in Diaspora, they conclude that some features are more related to security-by-design such as encryption features for securing user content. Diaspora is still in its beginnings with only a few users compared to global players (see Section 2.3). However it seems to bear some potential to improve SNS privacy. These and related developments ${ }^{24}$ are a sine qua non to find new mechanisms suitable for the main privacy challenges.

As Diaspora exemplifies, there exist some promising technical means available for enhancing privacyby-design. In general, there are an increasing number of privacy tools that aim at supporting users in their informational self-determination. For instance, browser plugins or add-ons such as Ghostery that

\footnotetext{
${ }^{23} \underline{\mathrm{http}}$ // / www.diasporial.com; https://joindiaspora.com; https://diasporafoundation.org

24 For instance, vanish is a promising approach to develop self-destructing digital data http://vanish.cs.washington.edu
} 
prevents third-party access to collect data of a user's Internet behaviour, different kinds of advertisement blockers (e.g. Adblockplus), or add-ons to block social plugins such as Facebookblocker, etc. Similar tools also exist as apps for SNS environments (e.g. privacyfix.com).

Such tools are without any doubt essential to foster privacy protection. However, from a wider societal perspective, these measures are often prophylactic and not sufficient to cope with existing privacy and data protection problems. One important aspect is that the employment of such technological means is currently in the responsibility of the individual. This depends not least on his or her amount of privacy awareness. This contributes to another form of digital divide: a sort of privacy divide (cf. Papacharissi 2010), where users with privacy awareness and capabilities to protect their data are separated from users with less awareness and/or less media and privacy literacy. While users have without any doubt high responsibility to protect their data and privacy, they cannot be the only ones to be in charge. Hence, instead of providing users with a cumbersome and sometimes diffuse tool-box to take care for their privacy, privacy-by-design needs to be improved on several levels accordantly. As regards SNS, this implies to enforce the implementation of privacy mechanisms in design and architecture of SNS in a more effective way than it is currently the case. Relevant factors in this regard are:

- Encryption of content

- Unlinkability of personal identifiable information

- Pseudonymity and options for anonymous usage

- Decentralization of personal data

- Transparency and accountability of SNS environments and providers

Content encryption is an essential aspect to improve the protection of several privacy types (as described in Section 5.2). Currently, this is widely the exception than the norm: most information is available online as plain text. Integrating encryption functionality as standard into the SNS environments would significantly contribute to protect the privacy of the user and to effectively secure from unintended information disclosure. The problem of increasing personal identifiable information can also be addressed with encryption, referring to the concept of unlinkability of personal information which is a major requirement for the implementation of informational self-determination. Unlinkability is essential to prevent from "privacy-destroying linkage and aggregation of identity information across data contexts" (Rundle et al. 2008). Options to use pseudonyms instead of unique identities, for instance by surrogating identifiers or parts of a user ID with random values supports to avoid linkage with users' identities. Pixelating techniques could be used by default to anonymize and remove the relation of a photo to a specific person; also in order to avoid automatic face recognition. Currently, most SNS represent centralized repositories containing massive amounts of personal information. As the example of Diaspora shows, there is also the option of a decentralized architecture. This also supports privacy and security and thus should be fostered. The integration of features enabling SNS users to view their own profile from different angles could support transparency and awareness, for instance by differentiating between how a user profile is presented to contacts, other users or the outside web, together with options to change the modes of presentation. A similar demand is given as regards system designs: these should be widely open to public scrutiny and verifiable as regards their handling of personal information. The use of open standards can contribute to enhance transparency and accountability of SNS.

These potential measures should not be misunderstood as merely technical means but should be supported by accordant policy actions such as:

- Enforce content encryption as standard

- Foster anonymity and pseudonymity

- Strengthen freedom of information and transparency

- Raise awareness for privacy and transparency

- Stimulate innovation for privacy by design 
- Strengthen the role of Data Protection Authorities to improve checks and balances

As described above, setting privacy as the default is a core aspect to foster privacy-by-design principles. Several valuable approaches including technical and organisational means in the field of privacy-bydesign exist. Innovations in this domain thus need to be stimulated and put forward on larger scale to cope with the privacy challenges. In this regard, the on-going reform of the European data protection legislation can play an important role. As contemporary privacy suffers from "the imbalanced control over personal information and increasing information asymmetries between the data controller and the individual whose data are processed" (Strauß 2013), there seems to be a policy vacuum in the currently effective legislation. Observing the on-going reform process, the European Commission seems to be well aware of this vacuum: The current proposal encompasses several relevant issues to support and promote privacy-by-design such as particular norms on data protection by design and by default, a strengthened role of privacy impact assessments, the obligatory creation of data protection officers in companies above a specific size, and the stimulation of economic incentives for privacy-by-design through data protection seals (such as the EuroPriSe seal25). In addition, the draft contains several suggestions to improve transparency of data processing, e.g. an obligation for data controllers "to explicitly inform the data subject on the legitimate interests pursued" by processing of personal data, the highlighting of purpose limitation and consent, the obligation to notify about data breaches, the provision to individuals of access to data concerning him or herself, the right not to be subject to profiling by means of automated processing as well as the right to be forgotten (EC 2012b).

As the reform is still in process, it is yet uncertain whether the results will properly address the challenges ahead. At least the current proposal seems promising as it fosters two essential aspects: privacy-by-design and transparency enhancement. If the implementation succeeds, some of the privacy challenges described in this report can be addressed in the context of SNS as well as on the outside web environments.

25 https:/ / www.european-privacy-seal.eu. 


\section{CONCLUDING REMARKS}

This report analyses the major characteristics of contemporary social network sites (SNS), their basic structure and functionality as well as potential effects and societal impacts. Being among the most controversial and topical aspects, a main part of the report focuses on privacy implications and options to address the respective challenges.

The rapid evolution of social media and SNS yielded a broad spectrum of novel forms of interaction. The design of SNS, primarily their networking structure, contributes much to people connecting worldwide for a variety of purposes. Around the most important reasons for usage, to stay in touch with others, manifold different motivations and usage patterns mirror societal heterogeneity. With their lowthreshold options to establish, modulate and extend various network-based relations, SNS highlight and foster the effects of many-to-many interactions. The effects of usage vary, but refer to general networking effects such as the strength of weak ties. To some extended traditional network effects are boosted by enhanced interactivity. In this regard, self-amplifying dynamics are inherent in SNS design: the number of users is likely to grow if interaction among them increases. This significantly contributes to enhanced options for widespread distribution of information in no time among large numbers of users, groups and communities locally and globally. This particular strength supports a variety of positive effects such as stimulating social learning, enabling new modes of participation, strengthening community building, developing social capital and enhancing political empowerment. However, as the case of the Arab Spring Revolutions highlights, the role of SNS for political participation is often ambivalent. The same social media channels that supported activists and democratic movements have been used by authoritarian regimes for control and repression. Hence, without individuals using social media for democratic means this potential lies idle. The many different interactive tools available in SNS also foster the production of new knowledge. This feeds the participatory capacity of SNS as well as knowledge production, particularly in scientific contexts. The large amount of content available via SNS can contribute to mutual learning among users and present valuable sources for various kinds of business models.

As the content can hardly be separated from the individual users, privacy protection is among the most controversial aspects in SNS. An essential concept that becomes increasingly strained is informational self-determination. SNS highlight that the array of different digital contexts, in which personal information flows through, keeps expanding. Recent innovations, such as the increasing role of social plugins and the social graph, amplify this expansion. As a result, informational self-determination becomes even more complicated as information processing and analysis is in most cases unrecognized at least by the individual users. And even if recognized, the options for users to control their privacy are limited and not sufficient. In addition, the responsibility to protect privacy cannot be merely resting on the individuals concerned. Instead, privacy protection is a shared responsibility among all stakeholders involved, i.e. the users, the SNS providers, civil society and policy makers.

Neglecting the need to foster privacy-by-design entails negative consequences for innovation and business development in Europe as privacy is also a matter of trust. Losing trust negatively affects the development of economic markets. At least two core problems of contemporary privacy protection can be identified that become reinforced by SNS environments: the disclosure-by-default paradigm, i.e. personal information becomes increasingly accessible as a standard, became dominant while privacy mechanisms become the exception rather than the norm. Furthermore, we observe that personal identifiable information increases considerably and the boundaries between personal and non-personal information blur. This is not least a result of the new modes of interactions enabling many-to-many relations between personal and non-personal entities. As a consequence, content and other digital objects can also be used to track back to one's identity. SNS already affect a variety of different privacy types and, considering emerging trends in relation to SNS, privacy impacts are likely to expand. For instance, social plugins and social graphs, which link SNS and outside Web environments, gather deep insights 
into user behaviour; biometrics and face recognition technologies are likely to grow wider into SNS contexts and undermine privacy in the physical as well as the virtual world; mobile SNS usage is among the fastest growing markets and via location-based services SNS also compile information about user movements in the analogue world.

To cope with these multiple privacy challenges ahead, a shift of the prevailing disclosure-by-default paradigm is necessary towards privacy-by-design and privacy-by-default schemes. This implies a set of accordant measures:

- Enforce content encryption as standard

- Foster anonymity and pseudonymity

- Strengthen freedom of information and transparency

- Raise awareness for privacy and transparency

- Stimulate innovation for privacy by design

- Strengthen the role of Data Protection Authorities to improve checks and balances

Encryption is an essential part in several of these measures to come to more appropriate and sufficient security and privacy-by-design concepts and solutions. At present, applications and services where content is encrypted are the wide exception in SNS as well as in most other Web applications. Stimulating the employment of encryption as quasi-standards for online-applications that handle personal (or quasi-personal) information contributes to alleviate a variety of contemporary privacy problems. To improve the effective enforcement of privacy-by-design principles, the role of Data Protection Authorities (DPAs) should be strengthened. This contributes to increasing the scrutiny of proper handling of personal information in SNS environments and beyond, as well as to enhancing the effectiveness of checks and balances. This seems particularly essential as recent mass surveillance scandals (namely PRISM and Tempora) drastically highlight that trust is a core achievement of democratic societies. As a mutual concept, both public and private institutions are well advised to reduce the loss of trust triggered by these scandals. Fostering privacy is overdue in the SNS context as well as beyond. 


\section{REFERENCES}

Acquisti, A. and Gross, R., 2006, Imagined Communities: Awareness, Information Sharing, and Privacy on the Facebook, in: Danezis, G. and Golle, P. (Eds): PET 2006, Heidelberg Springer, 36-58.

Al-Ani, A., 2013, Widerstand in Organisationen. Organisationen im Widerstand. Virtuelle Plattformen, Edupunks und der nachfolgende Staat; in series: Organisation und Gesellschaft: Springer VS Verlag für Sozialwissenschaften.

Amanda, L. and Mary, M., 2007, Social networking websites and teens: an overview: Pew Internet and American Life Project <http://apo.org.au/?q=node/16749>.

Article 29 Data Protection Working Party, 2009, Opinion 5/2009 on online social networking <http://ec.europa.eu/justice/policies/privacy/docs/wpdocs/2009/wp163_en.pdf >.

Article 29 Data Protection Working Party, 2010, European data protection group faults Facebook for privacy setting change (Press release, $12 \quad$ May) <http://ec.europa.eu/justice/policies/privacy/news/docs/pr_12_05_10_en.pdf>.

Baringhorst, S., 2009, Introduction. Political Campaigning in Changing Media Cultures - Typological and Historical Approaches, in: Baringhorst, S., Kneip, V. and Niesyto, J. (Eds): Political Campaigning on the Web, Bielefeld, 9-30.

Barnes, S. B., 2006, A privacy paradox: Social networking in the United States, First Monday 11(6) <http://firstmonday.org/issues/issue11_9/barnes/index.html>.

Benkirane, R., 2012, The Alchemy of Revolution: The Role of Social Networks and New Media in the Arab Spring. GCSP Policy Paper, No. 2012/7, edited by Geneva Center for Security Policy.

Biermann, K., 2010, Facebook, bing und Skype vernetzen sich, Zeit Online, 15.10. <http:// www.zeit.de/digital/internet/2010-10/facebook-bing-skype>.

Bonneau, J., Anderson, J., Anderson, R. and Stajano, F., 2009, Eight friends are enough: Social graphs $\begin{array}{lllll}\text { approximation via public listings, in: } & \text { 13-18 }\end{array}$ <http://www.cl.cam.ac.uk/ rja14/Papers/8_friends_paper.pdf>.

Boyd, D. M., 2007, Why Youth (Heart) Social Network Sites: The Role of Networked Publics in Teenage Social Life, in: Buckingham, D. (Ed.): MacArthur Foundation Series on Digital Learning - Youth, Identity, and Digital Media Volume, Cambridge, MA: MIT Press, 119-142 $<$ http://www.danah.org/papers/WhyYouthHeart.pdf $>$.

Boyd, D. M. and Ellison, N. B., 2007, Social Network Sites: Definition, History, and Scholarship, Journal of computer-Mediated Communication 13(1), $<$ http://jcmc.indiana.edu/vol13/issue1/boyd.ellison.html>.

Brandtdaeg, P. B. and Heim, J., 2009, Why people use social networking sites, in: Ozok, A. A. and $\begin{array}{lllll}\text { Zaphiris, } \quad \text { P. (Eds): Online Communities, LNCS 5621, 143-152 } & \end{array}$ $<$ http://www.academia.edu/907531/Why_People_Use_Social_Networking_Sites>.

Cachia, R., 2008, Social Computing: Study on the Use and Impact of Online Social Networking. IPTS Exploratory Research on the Socio-economic Impact of Social Computing: JRC Scientific and Technical Reports Institute for Prospective Technological Studies (IPTS) - European Commission <http://ftp.jrc.es/EURdoc/JRC48650.pdf >.

Cain, J., Scott, D. R. and Akers, P., 2009, Pharmacy Students' Facebook Activity and Opinions Regarding Accountability and E-Professionalism, American Journal of Pharmaceutical Education 73(6), Artikel $104<$ <ttp://www.ajpe.org/aj7306/aj7306104/aj7306104.pdf>.

Cavoukian, A., 2009, Privacy by Design ... Take the Challenge'; in series: Information and Privacy Commissioner of Ontario, Canada <http://www.privacybydesign.ca/content/uploads/2010/03/PrivacybyDesignBook.pdf>.

Clarke, R. C., 2006, What's 'Privacy'? <http://www.rogerclarke.com/DV/Privacy.html>.

CLG (Communities and Local Government), 2008, Online social networks research report, London: Communities and local government publications.

ComScore, 2012, More than Half of People that Access Social Networks on their Smartphone do so on a Near Daily Basis. comScore data mine (February 
<http://www.comscoredatamine.com/2012/02/ more-than-half-of-people-that-access-socialnetworks-on-their-smartphone-do-so-on-a-near-daily-basis>.

Dahlgren, P., 2013, Do social media enhance democratic participation? - The importance and difficulty of being realistic. Policy Paper No. 4/2013, edited by Rosa Luxemburg Stiftung Berlin

<http://www.rosalux.de/fileadmin/rls_uploads/pdfs/Standpunkte/policy_paper/PolicyPape r_04-2013.pdf $>$.

Debatin, B. and Lovejoy, J. P., 2009, Facebook and Online Privacy: Attitudes, Behaviors, and Unintended Consequences, Journal of Computer-Mediated Communication 15

Drucker, P. F., 1969, The Age of Discontinuity; Guidelines to Our changing Society, New York: Harper and Row.

Dwyer, C., Hiltz, S. and Passerini, K., 2007, Trust and Privacy Concern Within Social Networking Sites: A Comparison of Facebook and MySpace, in: Proceedings of the Thirteenth Americas Conference on Information Systems, Keystone, Colorado August 09 - 12 2007: Association for Information Systems<http://citeseerx.ist.psu.edu/viewdoc/download?doi=10.1.1.148.9388\&rep=rep1\&type $=$ pdf $>$.

EC (European Commission), 2009, Safer Social networking principles <http://ec.europa.eu/digitalagenda/sites/digital-agenda/files/sn_principles.pdf>.

EC (European Commission), 2011, Special Eurobarometer 359 Attitudes on Data Protection and Electronic Identity in the European Union, commissioned by: Directorate-General Information Society and Media (INFSO)/Directorate-General Justice (JUST)/Directorate-General JRC/DirectorateGeneral Communication ("Research and Speech Writing" Unit), June <http://ec.europa.eu/public_opinion/archives/ebs/ebs_359_en.pdf>.

EC (European Commission), 2012a, European Commission Digital Agenda Scoreboard 2012 <http://ec.europa.eu/digital-agenda/sites/digital-agenda/files/scoreboard_life_online.pdf>.

EC (European Commission), 2012b, Proposal for a REGULATION OF THE EUROPEAN PARLIAMENT AND OF THE COUNCIL on the protection of individuals with regard to the processing of personal data and on the free movement of such data (General Data Protection Regulation). COM (2012) 11 final. Brussels, 25.01. <http://ec.europa.eu/justice/dataprotection/document/review2012/com_2012_11_en.pdf>.

Ellison, N. B. and Boyd, D., 2013, Sociality through Social Network Sites, in: Dutton, W. H. (Ed.): The Oxford Handbook of Internet Studies, Oxford: Oxford University Press, 151-172.

Ellison, N. B., Steinfield, C. and Lampe, C., 2007, The Benefits of Facebook "Friends:" Social Capital and College Students' Use of Online Social Network Sites, Journal of Computer-Mediated Communication 12, 1143-1168

<http://www.mvirtual.com.br/midiaedu/artigos_online/facebook.pdf>.

Elmer, G., 2004, Profiling Machines, Cambridge, MA: MIT Press.

Ericsson, 2012, Ericsson Mobility Report - on the pulse of the networked society $<$ http://www.ericsson.com/ericsson-mobility-report>.

Ferdig, R. E., Dawson, K., Black, E. W., Black, N. M. P. and Thompson, L. A., 2008, Medical students' and residents' use of online social networking tools: Implications for teaching professionalism in medical education, First Monday 13(9)

<http://firstmonday.org/htbin/cgiwrap/bin/ojs/index.php/fm/article/viewArticle/2161/202 $6>$.

Finn, R. L., Wright, D. and Friedewald, M., 2013, Seven Types of Privacy, in: S. Gutwirth et al. (Ed.): European Data Protection: Coming of Age, Dordrecht: Springer Science+Business Media < http://works.bepress.com/michael_friedewald/60>.

Fraser, M. and Dutta, S., 2008, Throwing Sheep in the Boardroom: How Online Social Networking Will Transform Your Life, Work and World Hoboken et al.: Wiley.

Frazer, N., 2007, Transnationalising the Public Sphere: On the Legitimacy and Efficacy of Public Opinion in a Post-Westphalian World, Theory, Culture and Society 24, 7-30. 
Fuchs, C., 2009, Social Networking Sites and the Surveillance Society. A Critical Case Study of the Usage of studiVZ, Facebook, and MySpace by Students in Salzburg in the Context of Electronic Surveillance, Salzburg/Wien: ICT\&S Center (University of Salzburg), Forschungsgruppe Unified Theory of Information <http://twinic.com/duploads/0000/0509/ICT_Use_-

_MySpace_Facebook_2008.pdf $>$.

Fuchs, C., 2010, Facebook, Web 2.0 und ökonomische Überwachung, Datenschutz und Datensicherheit (DuD) (7), 453-.458.

Granovetter, M. S., 1973, The Strength of Weak Ties, American Journal of Sociology 78(6), 1360-1380.

Gross, R. and Acquisti, A., 2005, Information Revelation and Privacy in Online Social Networks (The Facebook case), in: Atluri, V., De Capitani di Vimercati, S. and al. (Eds): Proceedings of the 2005 ACM Workshop on Privacy in the Electronic Society, WPES 2005, Alexandria, VA, USA, November 7: ACM Press, 71-80.

Habermas, J., 1989, The Structural Transformation of the Public Sphere: An Inquiry into a Category of Bourgeois Society (original work: "Strukturwandel der Öffentlichkeit 1962, Hermann Luchterhand Verlag), Cambridge MA: The MIT Press.

Hargittai, E., 2007, Whose Space? Differences Among Users and Non-Users of Social Network Sites, Journal of Computer-Mediated $\quad$ Communication 13(1), 276-297 <http://onlinelibrary.wiley.com/doi/10.1111/j.1083-6101.2007.00396.x/pdf>.

Häusler, S., 2007, Soziale Netzwerke im Internet. Entwicklung, Formen und Potenziale zu kommerzieller Nutzung, Saarbrücken: VDM Verlag Dr. Müller.

Heidemann, J., 2010, Online Social Networks - Ein sozialer und technischer Überblick., InformaktikSpektrum 33 (2010), 262-271.

Hoffman, E. S., 2009, Evaluating Social Network Tools for Distance Learning, TCC 2009 Proceedings, 92100.

Humphreys, L., 2010, Mobile social networks and urban public space, New Media Society, 1-16 $<$ http://www.asc.upenn.edu/news/2010/Humphreys_journal.pdf>.

Islam, M. B. and Iannella, R., 2012, Privacy by Design: Does it matter for social networks?, in: B. Crispo et al. (Ed.): Privacy and Identity Management for Life IFIP Advances in Information and Communication Technology Berlin/Heidelberg: 207-220 <http://link.springer.com/chapter/10.1007/978-3-642-31668-5_16>.

Jin, L., Chen, Y., Wang, T., Hui, P. and Vasilakos, A. V., 2013, Understanding user behavior in online social networks: a survey, IEEE Communications Magazine September.

Kann, M. E., Berry, J., Gant, C. and Zager, P., 2007, The Internet and youth political participation, First Monday 12(8).

Kleinfeld, J. S., 2002, The small world problem, Society 39(2), 61-66 <http://www.stat.cmu.edu/ fienberg/Stat36-835/Kleinfeld_SWP.pdf>.

Lack, C., Beck, L. and Hoover, D., 2009, Use of social networking by undergraduate psychology majors, First Monday 14(12)

<http://firstmonday.org/htbin/cgiwrap/bin/ojs/index.php/fm/article/view/2540/2407>.

Leenes, R. (Ed.), 2010, Context is everthing: sociality and privacy in Online Social Network Sites, Heidelberg/Berlin/New York: Springer.

Lehavot, K., 2009, MySpace or Yours? The Ethical Dilemma of Graduate Students' Personal Lives on the Internet, Ethics \& Behavior 19(2), 129-141.

Leskovec, J. and Horvitz, E., 2008, Worldwide buzz: Planetary-scale views on a large instant-messaging network, in: Proceedings of the 17th international conference on World Wide Web, April 21-25, Beijing, 915-924.

Levine, P., 2002, Can the Internet save democracy? Toward an on-line commons, in: Hayduk, R. and Mattson, K. (Eds): Democracy's moment: Reforming the American political systems, New York, 121137.

Lewis, K., Kaufman, J. and Christakis, N., 2008, The Taste for Privacy: An Analysis of College Student Privacy Settings in an Online Social Network, Journal of Computer-Mediated Communication 14(1). 
Lindner, R., 2007, Politischer Wandel durch digitale Netzwerkkommunikation?, Wiesbaden.

Lindner, R., Beckert, B., Aichholzer, G., Strauß, S. and Hennen, L., 2011, E-public, e-participation and evoting in Europe - prospects and challenges; Final Report, commissioned by: Science and Technology Options Assessment (STOA)/European Parliament, Karlsruhe: Fraunhofer-Institut für System- und Innovationsforschung,

Livingstone, S., 2008, Taking risky opportunities in youthful content creation: teenagers' use of social networking sites for intimacy, privacy and self-expression, New media \& society 10(3), 393-411 $<$ http://eprints.lse.ac.uk/27072/1/Taking_risky_opportunities_in_youthful_content_creation_ $\% 28 \mathrm{LSERO} \% 29$.pdf $>$.

Macintosh, A., 2003, Using Information and Communication Technologies to Enhance Citizen Engagement in the Policy Process, in: OECD (Ed.): Promise and Problems of E-Democracy. Challenges of Online Citizen Engagement, Paris, 19-142.

Mack, D., Behler, A., Roberts, B. and Rimland, E., 2007, Reaching Students with Facebook: Data and Best Practices, Electronic Journal of Academic and Special Librarianship 8(2) <http://southernlibrarianship.icaap.org/content/v08n02/mack_d01.html>.

McLuhan, M., 1964, Understanding Media. The Extensions of Man, London: Routledge \& Kegan Paul.

McQuail, D., 1994, Mass communication theory: an introduction, London Sage.

Milgram, S., 1967, The small world problem., Psychology Today 2(1), 60-67.

Nanz, P., 2007, Multiple Voices: An Interdiscursive Concept of the European Public Sphere, in: Fossum, J. E., Schlesinger, P. and Kvaerk, G. (Eds): Public Sphere and Civil Society? Transformations of the $\begin{array}{lllll}\text { European Union. ARENA Roport } & \text { 11-28 }\end{array}$ <http://www.arena.uio.no/cidel/Reports/702.pdf.>.

Nentwich, M., 2003, Cyberscience: Research in the Age of the Internet, Vienna: Austrian Academy of Sciences Press <http:/ /hw.oeaw.ac.at/3188-7>.

Nentwich, M. and König, R., 2012, Cyberscience 2.0. Research in the Age of Digital Social Networks; in series: Interactiva, Vol. 11, edited by Bieber, C., Leggewie, C. and Lobin, H., Fankfurt/New York: Campus

<http://www.campus.de/wissenschaft/kulturwissenschaften/Kommunikation+und+Medien.4 0449.html/Cyberscience+2.0.98243.html>.

Nextmedia CSA, 2010, Social Networks Overview: Current Trends and Research Challenges. European Commission Information Society and Media.

OECD, 2007, Participative Web and User-Created Content. Web 2.0, Wikis and social networking: Organisation for economic co-operation and development <http://akgul.bilkent.edu.tr/oecd/9307031E.pdf >.

Papacharissi, Z., 2010, Privacy as luxury commodity, First Monday, 8 <http://firstmonday.org/ojs/index.php/fm/article/view/3075/2581>.

Power, R., 2011, Face recognition and social media meet in the shadows, CSO Online, August 01 $<$ http://www.csoonline.com/article/686959/face-recognition-and-social-media-meet-in-theshadows $>$.

Pratchett, L., Durose, C., Lowndes, V., Smith, G., Stoker, G. and Wales, C., 2009, Empowering communities to influence local decision making. Evidence-based lessons for policy makers and practioners.

Preece, J., 2000, Online communities: designing usability, supporting sociability, Chichester: Wiley.

Rantamäki, J., 2008, Perceived user value of social networking <http://www.cse.hut.fi/en/publications/B/1/papers/Rantamaki_final.pdf>.

Rheingold, H., 1993, The Virtual Community: Homesteading on the Electronic Frontier, Reading AddisonWesley.

Richter, A. and Koch, M., 2007, Social Software - Status quo und Zukunft; Technischer Bericht, No. 2007-01, Februar 2007, München: Fakultät für Informatik, Universität der Bundeswehr München <http://www.unibw.de/wow5_3/forschung/social_software>. 
Rogers, R., 2009, Zur Frage der Vergoogelung. Hin zu einer unkritisierbaren Maschine?, in: Becker, K. and Stalder, F. (Eds): Deep Search. Politik des Suchens jenseits von Google, Innsbruck: Studienverlag, 193-206.

Röll, F. J., 2010, Social Network Sites. Digitale Jugendkulturen, in: Hugger, K.-U. (Ed.): VS Verlag für Sozialwissenschaften, 209-224 <http://dx.doi.org/10.1007/978-3-531-91908-9_12>.

Rundle, M., Blakley, B., Broberg, J., Nadalin, A., Olds, D., Ruddy, M., Guimarares, M. T. M. and Trevithick, P., 2008, At a crossroads: "Personhood" and digital identity in the information society, No. JT03241547: OECD <http://www.oecd.org/dataoecd/31/6/40204773.doc>.

Schaefer, C., 2008, Motivations and usage patterns on social network sites, in: Proceedings of the 16th European Conference on Information Systems (ECIS), Galway, Ireland.

Schmidt, J., 2009, Das neue Netz. Merkmale, Praktiken und Folgen des Web 2.0, Konstanz: UVK.

Singh, N., Lehnert, K. and Bostick, N., 2012, global social media usage - Insights Into Reaching Consumers Worldwide, Wiley Online Library, DOI: 10.1002/tie.21493 <http://beople.es/wpcontent/uploads/2013/04/GLOBAL-SOCIAL-MEDIA-USAGE-INSIGHTS-INTO-REACHINGCONSUMERS-WORLDWIDE.pdf>.

Skinner, J., 2012, Social Media and Revolution: The Arab Spring and the Occupy Movement as Seen Through Three Information Studies Paradigms. Working Papers on Information Systems $<$ http://sprouts.aisnet.org/11-169>.

Smith, A., 2011, Why American use social media: Pew Research Center, <http://www.pewinternet.org/ /media/Files/Reports/2011/Why\%20Americans\%20Use\%20 Social\%20Media.pdf>.

Solove, D., 2006, A taxonomy of privacy, University of Pennsylvania Law Review 154 (3), 477-560.

Steinfield, C., Ellison, N. B. and Lampe, C., 2008, Social capital, self-esteem, and use of online socialnetworksites: A longitudinal analysis, Journal of Applied Developmental Psychology 29(6), 434-445.

Strauß, S., 2011, The Limits of Control - (Governmental) Identity Management from a Privacy Perspective, in: Fischer-Hübner, S. (Ed.): Privacy and Identity Management for Life, 206-218.

Strauß, S., 2013, Digital identities and the upcoming EU privacy reform - a future-proof approach?, LSE Media Policy Project Blog, London School of Economics and Political Science <http://blogs.lse.ac.uk/mediapolicyproject/2013/05/08/digital-identities-and-the-upcomingeu-privacy-reform-a-future-proof-approach/ $>$.

Strauß, S. and Nentwich, M., 2013, Social network sites, privacy and the blurring boundary between public and private spaces, Science and Public Policy (6), doi: 10.1093/scipol/sct072 <http://spp.oxfordjournals.org/content/early/2013/10/10/scipol.sct072.full>.

Trenz, H. J., 2008, In search of the European Public Sphere. Between Normative Overstretch and Empirical Disenchantment. RECON Online Working Paper.

Valkenburg, P. M., Peter, J. and Schouten, A. P., 2006, Friend Networking Sites and Their Relationship to Adolescents' Well-Being and Social Self-Esteem CyberPsychology \& Behavior 9(5), 584-590.

Van der Berg, B., 2011, The uncanny valley everywhere? On privacy perception and expectation management, in: Fischer-Hübner, S., Duquenoy, P., Hansen, M., Leenes, R. and Zhang, G. (Eds): Privacy and identity management for life: 6th IFIP WG 9.2, 9.6/11.7, 11.4, 11.6/PrimeLife International Summer School: Springer, 178-191.

Wanhoff, T., 2011, Wa(h)re Freunde - Wie sich unsere Beziehungen in sozialen Online-Netzwerken verändern, Heidelberg: Spektrum Akademischer Verlag.

Warren, S. D. and Braneis, L. D., 1890, The Right to Privacy, Harvard Law Review 193 (5) $<$ http://faculty.uml.edu/sgallagher/Brandeisprivacy.htm>.

Waterson, P., 2006, Motivation in Online Communities, in: Dasgupta (Ed.): Encyclopedia of Virtual Communties.

Westin, A., 1967, Privacy and freedom, New York: Atheneum. 
Wimmer, J., 2009, The Publics behind Political Web Campaigning. The Digital Transformation of 'Classic' Counter-Public Spheres, in: Baringhorst, S., Kneip, V. and Niesyto, J. (Eds): Political Campaigning on the Web, Bielefeld: transcript, 31-51.

Wondracek, G., Holz, T., Kirda, E. and Kruegel, C., 2010, A Practical Attack to De-Anonymize Social Network Users; Technical report: iSecLab. <http:/ / tinyurl.com/yccfqqd>. 
The opportunities of using powerful computing resources on demand via the web are considered as a possible driver for the growth of the European economy. While the market for Social Network Sites has already experienced a consolidation, the market for Cloud Computing is still in an early stage, but with considerable growth rates. In addition the recent massive surveillances actions and the rise of cyber-crime showed the need for a more secure basis of future computing. As a result it is necessary to support the development of highly secure IT solutions. By modernizing the data protection regime Europe could not only ensure the better protection of citizens, but also serve as a model and partner for emerging markets. In order to encourage this evolution the digital life of citizens and business needs legal certainty to ensure new ideas are taken up. As well as this it is abundantly clear that a crucial precondition for a competitive ICT industry is an inspiring surrounding ecosystem.

This is a publication of Science and Technology Options Assessment Directorate for Impact Assessment and European Added Value Directorate-General for Parliamentary Research Services, European Parliament 